\section{Ankara Üniversitesi Eğitim Bilimleri Fakültesi Özel Eğitim Dergisi}

2022, 23(2), 365-388
ARAŞTIRMA

Gönderim Tarihi: 10.03 .20

Kabul Tarihi: 28.07.21

Erken Görünüm: 02.09.21

\title{
Öğrenme Güçlüğü Olan ve Olmayan Öğrencilerde Akıcı Okuma ve Okuduğunu Anlama Becerileri Arasındaki İlişkinin İncelenmesi
}

\author{
Gülperi Arabaci iD1
}

$\ddot{O} z$

Giriş: Bu çalışmada, dördüncü sınıfa devam eden 55 öğrencinin (27'si öğrenme güçlüğü olan ve 28'i tipik gelişim gösteren) akıcı okuma ve okuduğunu anlama becerilerindeki performansları ve her iki beceri arasındaki ilişki düzeyinin belirlenmesi amacıyla karşılaştırmalı olarak incelenmesi amaçlanmıştır.

Yöntem: Çalışmada nicel araştırma yöntemlerinden ilişkisel tarama modeli kullanılmıştır. Katılımcıların akıcı okuma (doğru okuma, hız ve prozodi) ve okuduğunu anlama becerileri dördüncü sınıf düzeyinde geçerliği ve güvenirliği sağlanmış iki metin ve çoktan seçmeli test soruları ile veri toplanarak incelenmiştir. Araştırma verilerinin analizi SPSS 18.00 istatistik programı ile yapılmıştır.

Bulgular: Çalışmadan elde edilen bulgulara göre; öğrenme güçlüğü olan öğrencilerin akıcı okuma ve okuduğunu anlama becerilerinde tipik gelişim gösteren öğrencilere göre anlamlı şekilde daha düşük puan aldıklarını göstermiştir. Akıcılık ve okuduğunu anlama arasındaki ilişkiler incelendiğinde öğrenme güçlüğü olan öğrencilerde okuma hızı ile okuduğunu anlama arasında, tipik gelişim gösteren öğrencilerde ise prozodi ile okuduğunu anlama arasında pozitif yönlü orta düzeyde anlamlı bir ilişki olduğu görülmüştür.

Tartışma: Bu araştırmada, öğrenme güçlüğü olan öğrencilerin hem akıcı okuma hem de okuduğunu anlamada akranlarının önemli ölçüde gerisinde oldukları ve bu becerilerinin geliştirilmesi gerektiği belirlenmiştir. Tipik gelişim gösteren akranlarının okuma becerilerinde önemli derecede ilerlediği ve öğretimin diğer akademik alanlardaki öğrenmeye daha çok odaklandığı dördüncü sınıfta yaşadıkları bu okuma problemlerinin daha sonraki yıllarda yaşanacak akademik başarısızlıklara neden olacağı kaçınılmazdır.

Anahtar sözcükler: Öğrenme güçlüğü, akıcı okuma, doğru okuma, okuma hızı, prozodi, okuduğunu anlama.

Atıf için: Arabacı, G. (2022). Öğrenme güçlüğü olan ve olmayan öğrencilerde akıcı okuma ve okuduğunu anlama becerileri arasındaki ilişkinin incelenmesi. Ankara Üniversitesi Ĕ̆itim Bilimleri Fakültesi Özel Ĕ̈itim Dergisi, 23(2), 365-388. https://doi.org/10.21565/ozelegitimdergisi.700711

${ }^{1}$ Doktora Öğrencisi, Eskişehir Osmangazi Üniversitesi, E-posta: gulperiardc@gmail.com, https://orcid.org/0000-0002-89879984 


\section{Giriş}

Öğrenme güçlüğü (ÖG), yazılı ve sözlü dili anlama ve kullanmada temel olan bir veya daha fazla psikolojik sürecin etkilenmesiyle ortaya çıkan dinleme, düşünme, konuşma, okuma, yazma ve matematiksel hesaplamalar yapmadaki güçlükler olarak tanımlanmaktadır. Okuma, yazma, matematik, bilgiyi işlemleme, bellek-bilişsel ve üstbilişsel stratejilerin kullanımı, görsel ve işitsel algıı, dikkat, dili anlama ve kullanma (konuşma dili, yazı dili) becerilerinde yaşanan güçlükler ile karakterize olan ÖG, özel eğitime gereksinim duyan grupların en büyük kısmını oluşturmaktadır (Senate Labor and Human Resources Committee, 1997). Bildirilen istatistiklere göre, Amerika Birleşik Devletleri’nde okuma güçlüğü yaklaşık \%80 gibi bir oranla diğer ÖG kategorilerine nazaran daha yaygın olarak rastlanmaktadır (Lerner, 2000; Shaywitz, 2003; Thompson \& Bushnell, 2009). Son Amerikan Psikiyatri Birliği (2013) Ruhsal Bozuklukların Tanısal ve İstatistiksel El Kitabı'na (DSM-5) göre disleksi (okuma güçlüğü), sözcük tanıma ve doğruluğu ya da akıcılığı sorunları, anlaşılır dile çevirme/yorumlama güçlüğü ve harf harf söyleme/yazma güçlükleri ile belirli öğrenme güçlükleri örüntüsünü göstermek için kullanılan bir terimdir. ÖG olan öğrencilerin tüm bu belirtilen güçlükleri düşünüldüğünde, özellikle akademik becerilerdeki başarının temeli olan okuma alanındaki yoğun gereksinimlerinin karşılanması ve akademik gelişimlerinin desteklenmesi oldukça önemlidir (Doğanay-Bilgi, 2017).

Okuyucuların yazılı metinlerde yer alan sözcükleri uygun ortografik, sesbilgisel ve morfolojik bilgi ve becerilerini kullanarak çözümleme, ardından çözümlenen sözcükleri var olan sözcük dağarcığı ile ilişkilendirerek anlamlandırma, anlamlandırılan sözcüklerden oluşan cümleleri sözdizimsel özellikleri bağlamında analiz edip verilmek istenen mesaja ulaşma gibi birçok görevin yer aldığı okuma (Güldenoğlu vd., 2019; Keskinkılıç \& Keskinkılıç, 2005; Wong vd., 2008) tüm akademik öğrenmelerinin temelini oluşturan karmaşık bilişsel ve dilsel bir süreçtir (Afflerbach vd., 2008; Harwell, 2001). Mercer ve Pullen (2005), okumanın sözcük çözümleme, akıc1lık ve anlama gibi üç ana aşamayı içerdiğini ifade etmektedir. Sözcük çözümleme aşaması, harf-ses ilişkisini anlamayı yani bir sesi temsil eden harfi sese dönüştürmeyi içermektedir. Çözümleme, sözcüklerin doğru bir şekilde sesletilmesidir. Akıcılık, sözcüklerin çözümlemeye ihtiyaç duyulmaksızın otomatik olarak tanınması ve okunması aşamasıdır. Daha az çaba sarfedilerek gerçekleştirilen okuma becerisi anlamaya temel oluşturur. Anlama aşamasında ise bireyin, metindeki sözcüklerin anlamına ulaşması ve dolayısıyla metinden anlam çıkarması söz konusu olmaktadır. Dolayısıyla, okumanın temel amacının akıcı okuma ve okuduğunu anlama olduğu ifade edilmektedir (Karasu vd., 2011).

Akıcılık metni doğru, hızlı ve uygun bir ifade ile okuma becerisidir (Bursuck \& Damer, 2007; Kuhn \& Stahl, 2003; Lai vd., 2014; Mercer \& Mercer, 2005; Tankersly, 2003). Sözcükleri doğru ve hızlı bir şekilde kolayca tanıyan bireyler akıcı bir şekilde okurlar (Lerner, 2000; National Reading Panel, 2013; Wong vd., 2008). Sözcük tanıma becerilerinin erken edinimi, okuma gelişimi için oldukça önemli bir süreçtir (Wood, 2008). Öğrenciler sınıf düzeyleri arttıkça, farklı metin türleri ve konular ile karşılaşmaktadır. Bununla beraber, yeni sözcükler ve çoklu anlamları tanımaktadırlar (Paige \& Lavell-Magpuri, 2014). Bazı öğrenciler bu süreçte akıcı okuyucular olarak zorlanmadan eğitimlerine devam ederken bazıları akıcı okumada zorluk çekmektedir. Bu nedenle, akıcı okumanın kazanılması birçok öğrenci için önemli bir aşama olarak değerlendirilmektedir (Pesa \& Somers, 2007). Alanyazında akıcı okumanın üç temel bileşenden oluştuğu ifade edilmektedir. Bunlar doğruluk, hız ve prozodidir (Ateş \& Yıldız, 2011; Baştuğ \& Akyol, 2012; Bursuck \& Damer, 2007; Hudson vd., 2005; Mercer \& Pullen, 2005; Rasinski, 2006). Doğruluk, metindeki sözcüklerin harf-ses uyumuna uygun bir şekilde seslendirilip okunmasıdır (Başaran, 2013). Adams (1990), sözcük tanıma sürecinde bireyin görsel uyaran olan yazı ile onun bellekte yer alan kodları ve anlamları ile ilişki kurduğunu ve böylece sözcüğün doğru seslendirildiğini belirtmektedir. Sözcüğü ayırt etmede ise okuyucu sözcükleri hem doğru seslendirmekte hem de anlamını oluşturmaktadır (Çaycı \& Demir, 2006).

Öğrencilerin okuma doğruluk düzeyleri bağımsız, öğretimsel ve endişe (başarısız) düzeyi olmak üzere üç düzeyde sınıflandırılmaktadır (Baydık, 2012). Bağımsız düzeyde okuma becerisine sahip bir öğrencinin sınıf düzeyindeki metinlerde yer alan sözcüklerin en az \%95'ini doğru okuyabilmesi beklenmektedir. Okuma doğruluğu $\% 90$ ve \%95 arasında olan öğrenciler, o sınıf düzeyindeki metinlerde öğretimsel düzeyde doğruluğa sahiplerdir. $\mathrm{Bu}$ düzeyde okuma yapabilen öğrencilerin beklenene yakın bir performansa sahip olduğu ancak hala desteklenmeleri gerektiği ifade edilmektedir. Okuma doğruluğu \%90'1n altında olan öğrencilerin ise endişe düzeyinde okudukları dolayısıyla doğru okuma becerilerinin sınıf düzeyinin oldukça gerisinde olduğu ve bu nedenle de desteklenmeleri gerektiği belirtilmektedir (Mercer \& Mercer, 2005). Juul ve diğerlerinin (2014) okumaya yeni başlayan Danimarkalı 172 öğrenci ile yaptıkları boylamsal çalışmada öğrenciler \%70 okuma doğruluk düzeyine ulaştıklarında sözcük tanıma hızının gelişmeye başladığı bulunmuştur. Araştırma sonucunda ögretmenlerin okuma hızından önce okuma doğruluğu gelişimine önem vermesi gerektiği vurgulanmıştır. 

BECERILLERI ARASINDAKİ İLİSKININ İNCELENMESİ

Akıcı okumanın diğer bileşeni olan okuma hızı ise sözcüklerin hızlı ve otomatik bir şekilde tanınması sürecini içermektedir (Nathan \& Stanovich, 1991; Rasinski, 2012). LaBerge ve Samuels'e (1974) göre otomatiklik okuma sürecinde hızlı, doğru ve fazla çaba sarf etmeden sözcük tanıma olarak tanımlamaktadırlar. Okumada güçlük çeken bireylerin birçoğu otomatik okumada güçlük çekerler (Hook \& Jones, 2002; Hudson vd., 2005; Lerner, 2000). Rasinski ve diğerlerine (2012) göre birey sözcük tanıma sürecini daha kolay, hızlı ve doğru bir şekilde gerçekleştirdikçe çözümleme süreci daha otomatik olarak gerçekleşmektedir. Okuma ancak bu şekilde gerçekleştirildiğinde sınırlı bir kapasite olarak tanımlanan bilişsel kaynaklar okuduğunu anlamaya yönlendirilebilmektedir (Lai vd., 2014; Wong vd., 2008).

Akıcı okumanın diğer bir bileşeni olan prozodi ise konuşmanın ritmik ve tonlamaya ait özelliklerini betimleyen dilsel bir terimdir ve prozodik okuma uygun ifade ile ritmik ve melodik olarak konuşurcasına okuma becerisidir (Ateş \& Yıldız, 2011; Baştuğ \& Keskin, 2012; Dowhower, 1991). Prozodik okuma çözümleme becerisi akıcı hale geldikten sonra gelişmektedir (Schwanenflugel vd., 2004). Hudson ve diğerlerine (2005) göre okuma prozodisi zayıf olan okurlar, sözcükleri ve sözcüklerin ifadelerini anlamsız ve uygunsuz bir şekilde gruplarlar ve bu anlamsız gruplamalardan dolayı da okuduklarını anlamada sorun yaşarlar. Diğer taraftan, öğrencinin metni anlaması okuduğunu uygun vurgu ve tonlamalarla daha prozodik okumasını da sağlamaktadır (Mercer \& Pullen, 2005).

Karmaşık bir süreç olarak değerlendirilen ve okumanın temel amacı olan okuduğunu anlama ise önemli bir öğrenme aracıdır (Adams, 1990; Anastasiou \& Griva, 2009; Edmonds vd., 2009; Lai vd., 2014; Lerner, 2000; Quellette, 2006). Ancak okuduğunu anlayabilen bireyler okuma yoluyla öğrenmeyi gerçekleştirebilmektedir. Buna karşın, okuduğunu anlamanın gerçekleşmesi için öncelikli olarak okunan metnin doğru, akıcı ve prozodik bir şekilde okunması gerekmektedir (Dündar \& Akyol, 2014). Bir cümleyi anlamak için birey görsel olarak sözcükleri tanımalı, çözümlemeli, sözcüklerin sesbilgisel, bütünsel özelliklerini cümlenin altında yatan anlama ulaşması için birbiriyle ilişkilendirip yorumlamalı ve değerlendirmelidir (Karatay, 2009; Kendeou vd., 2014).

Okuma üzerine yapılan yapılan araştırmalar, akıcı okumanın okuduğunu anlama becerisi için önemli ve gerekli olduğunu göstermiştir (Nathan \& Stanovich, 1991; Pikulski \& Chard, 2005; Wise vd., 2010). LaBerge ve Samuels'e (1974) göre, sözcük tanıma süreci akıcı olduğunda, okuyucu bilişsel kapasitesinin çoğunu metni anlamaya odaklayabilmektedir. Tersi durumda sözcük tanıma sürecinde çok zorlanan bir okuyucu bilişsel kapasitesinin çoğunu sözcük tanıma sürecine ayırdığından okuduğunu anlamaya yeterli bilişsel kapasite ayıramamaktadır (Ribeiro vd., 2016; Swanson \& O’Connor, 2009). Bu durumda okur okuduklarını unutabilmekte ve okurun anlama ulaşması mümkün olmamaktadır (Fuchs vd., 2001; LaBerge \& Samuels, 1974; Uzunkol, 2013; Wong vd., 2008). Bu bağlamda, ÖG olan öğrencilerin sözcük tanımada çok zorlandıkları, tüm dikkatlerini ve bilişsel süreçlerini çözümlemeye yönlendirdikleri ve dolayısıyla metinden anlam çıkarmada güçlük yaşadıkları ifade edilmektedir (Therrien, 2004; Wong vd., 2008). Ayrıca, prozodik okuyamayan okuyucuların da anlama süreçlerini okumadaki temel sözdizimsel, anlamsal ayrımlar ve ses perdesindeki değişikliklerle destekleyemedikleri belirtilmektedir (Miller \& Schwanenflugel, 2008). Çeşitli sinıf düzeylerinde bulunan öğrencilerde okuma akıcılığı ve okuduğunu anlama arasındaki ilişkinin incelendiği araştırmaların sonuçları, öğrencilerin akıcı okuma ve okuduğunu anlama performansı arasında anlamlı ve yüksek bir ilişki olduğunu göstermiştir (Başaran, 2013; Baştuğ \& Akyol, 2012; Baştuğ \& Keskin, 2012; Hitchcock vd., 2004; Kim vd., 2012; Klauda \& Guthrie, 2008; McConnaughhay, 2008; Rasinski vd., 2009; Ribeiro vd., 2016). Örneğin, Ribeiro ve diğerleri (2016) tarafından ikinci ve dördüncü sınıfta okuyan 159 öğrenci ile yapılan çalışmada, ikinci sınıfta akıcılık becerisinin okuduğunu anlamanın güçlü bir yordayıcısı olduğu bulunmuştur. Yazarlar bu sonuçlar temelinde ilkokulun ilk yıllarında doğru ve akıcı okumanın geliştirilmesinin önemine dikkat çekmişlerdir. Rasinski ve diğerleri (2009) üçüncü, beşinci ve yedinci sınıflarla yaptığı çalışmada her üç sınıf düzeyinde de akıcı okuma ve okuduğunu anlama arasında yüksek bir ilişki olduğunu ve okuma akıcılığında prozodinin önemli bir bileşen olduğunu belirtmişlerdir. Başaran (2013) ise 90 dördüncü sınıf öğrencisi ile yaptığı çalışmada akıcı okumanın okuduğunu anlamanın bir yordayıcısı olduğunu, prozodinin doğruluk ve hıza göre derinlemesine anlam oluşturmayı daha iyi yordadığını, doğru okumanın ise yüzeysel anlam oluşturmayı daha güçlü yordadığını bulmuştur. Baştuğ ve Keskin (2012) beşinci sınıf farklı cinsiyet, sosyoekonomik ve başarı düzeyindeki 39 öğrenciyle, akıcı okuma becerileri (doğruluk, hız, prozodi) ile yüzeysel ve çıkarımsal anlama arasındaki ilişkiyi incelediği çalışmalarında ilgili değişkenler arasında pozitif yönlü ve orta düzey ilişki bulmuştur. Akıcı okuma boyutlarından prozodinin hem basit hem de çıkarımsal anlama ile daha güçlü bir ilişkisi olduğu ve üç akıcı okuma becerisinin de çıkarımsal anlamayla basit anlamadan daha güçlü ilişkiler gösterdiği bulunmuştur. Bu sonuçlar akıc1 okumanın çıkarımsal anlamada etkili ve önemli bir bileşen olduğu şeklinde yorumlanmıştır. 

BECERILERİ ARASINDAKİ İLIȘKININ İNCELENMESI

Okuma akıcılığının tüm bileşenlerinin okuduğunu anlama ile olan ilişkisini ayrı ayrı inceleyen çalışmalar da bulunmaktadır. Bunlardan, O’Connor (2017) 337 okuma güçlüğü olan ve 150 tipik gelişim gösteren (TGG) öğrenci ile okuma akıcılığının okuduğunu anlama ile olan ilişkisini inceleyen çalışmasında hızlı okumanın okuduğunu anlama üzerinde sadece belirli bir noktaya kadar katkısı olduğunu belirtmiştir. Okuma güçlüğü olan ikinci sınıf öğrencilerinde dakikada 35 ila 75 sözcüğe kadar dördüncü sınıf öğrencilerinde ise dakikada 40 ila 90 sözcüğe kadar doğru okumanın okuduğunu anlama oranını arttırdığı gözlenmiştir. Ancak, okuma hızlarının daha fazla artmasının okuduğunu anlama üzerinde doğrudan bir fayda sağlamadığı görülmüştür. Diğer yandan, TGG öğrencilerden elde edilen sonuçlar diğer çalışmalarla tutarlılık göstermektedir. Buna göre, dördüncü sınıf öğrencilerinin dakikada okuduğu doğru sözcük sayısı 120 ila 140 sözcüğü geçtiğinde okuma hızının okuduğunu anlama üzerinde herhangi bir etkisi olmadığı belirtilmiştir. Kim ve diğerleri (2012) 270 birinci ve ikinci sınıf öğrencisiyle yaptıkları boylamsal çalışmada öğrencilerin okuma akıcılığı, sesli ve sessiz okuma akıcılığı, dinlediğini anlama ve okuduğunu anlama becerilerinin okuma becerileri geliştikçe değişip değişmediğini incelemişlerdir. Araştırma sonuçlarına göre, birinci sınıfta sözcük okuma akıcılığ 1 okuduğunu anlama ile ilişkili bulunurken ikinci sınıfta ilişkili bulunmamıştır. Bunun aksine, ikinci sınıfta metin okuma akıcılığı ile okuduğunu anlama arasında ilişki bulunmuştur. Sesli ve sessiz okuma akıcılıkları kıyaslandığında ise, birinci sınıfta sesli okuma akıcılığı, ikinci sınıfta ise sessiz okuma akıcılığı ile okuduğunu anlama arasında anlamlı ilişki olduğu belirlenmiştir.

Akıcılık becerisi okuduğunu anlama için önemli bir önkoşul ve yordayıcı olmasına rağmen Türkiye'de ilkokul öğretim programlarında akıcı okuma becerilerinin gelişimine yeterince önem verilmediği belirtilmektedir (Baştuğ \& Akyol, 2012). Öğretmenler çoğunlukla öğrencilerin sözcükleri doğru okuma becerileri üzerinde durmakta, diğer akıcılık becerilerine gereken önemi göstermedikleri düşünülmektedir (Ergül, 2012). Ayrıca, okuma güçlüğü olan öğrencilerde geleneksel yöntemle yapılan öğretim uygulamalarının, bu öğrencilere akıcılık ve anlama becerilerini kazandırmada yetersiz kaldığı ifade edilmektedir (İnce-Cora, 2007; Malone \& Mastropieri, 1992). Öğretmenlerin okumaya yönelik destek eğitim programları ile ilgili bilgileri de çoğunlukla yetersizdir (Ergül, 2012). Dolayısıyla okuma güçlüğü olan öğrenciler, aynı sınıf düzeyinde bulunan akranlarından önemli ölçüde geride kalmaktadırlar. Uygun müdahale programları yapılmadığında okumada yaşanan bu güçlükler sonraki yıllarda da artarak devam etmektedir. ÖG olan bireylerin birbirini etkileyen özellikleri; öğrenilmiş çaresizlik, uyumsuz denetim odağ gibi faktörler öğrenmeye karşı olumsuz tutum geliştirmelerine neden olduğu dolayısıyla düşük özgüven, sosyal izolasyon, motivasyon eksikliği gibi sorunlara yol açtığı bilinmektedir (Özmen, 2017). Ülkemizde genel olarak akıcılık ve okuduğunu anlama üzerine çalışmalar ile ÖG olan öğrencilerde bu alanlardaki performanslarının değerlendirildiği ve aralarındaki ilişkinin incelendiği çalışmalar (Gökçe-Sarıpınar \& Erden, 2010) oldukça sınırlı olmakla birlikte kullanılan yöntem bakımından da bu çalışmadan farklıdır. Bununla birlikte sadece akıcılık becerisini (Akyol \& Kodan, 2016; Çeliktürk-Sezgin \& Akyol, 2015; Ergül, 2012; GüzelÖzmen, 2005; Seçkin-Yılmaz \& Baydık, 2017; Uzunkol, 2013) ya da sadece okuduğunu anlama becerisini (BahapKudret \& Baydık, 2016; Fırat \& Ergül, 2020; Kocaarslan, 2019) inceleyen çalışmaların da olduğu görülmektedir. Bu çalışmalarda genel olarak, ÖG tanısı olan çocukların, TGG çocuklarla karşılaştırıldığında, okuma becerileri açısından anlamlı derecede düşük puanlar aldıkları, daha çok okuma hataları yaptıkları, okuma hızlarının ve okuduğunu anlama becerilerinin düşük olduğu, okurken noktalama işaretlerine, tonlama ve vurgulamalara dikkat etmedikleri belirlenmiştir (Akyol \& Kodan, 2016; Gökçe-Sarıpınar \& Erden, 2010; Güzel-Özmen, 2005; SeçkinYılmaz \& Baydık, 2017). Sadece TGG grubuna yönelik karşılaştırma çalışmalarındaki sık sık belirtilen bir bulgu ise okuduğunu anlama becerisi ile en yüksek ilişki gösteren akıcı okuma becerisinin prozodi olduğu ve prozodik okuyan öğrencilerin okuduklarını daha iyi anladıkları olmuştur (Başaran, 2013; Baştuğ \& Akyol, 2012; Baştuğ \& Keskin, 2012).

Okumada güçlük yaşayan öğrencilerin belirlenmesi, öğrencilerin gereksinim duyduğu alanlarda desteklenmesi, öğretmenlerin ise öğrencilerin bireysel gereksinimlerini karşılayacak şekilde öğretimi planlamaları ve gerekli uyarlamaları yapmaları önemlidir. Türkiye'deki alanyazın incelendiğinde, öğrencilerin akıcı okuma ve okuduğunu anlama performansının değerlendirilmesi ve ÖG olan öğrencilerin bu becerilerdeki sorunları için farklı yaş gruplarıyla ve stratejilerle müdahale programlarının hazırlanması gerekmektedir. Bu çerçevede, bu çalışmada ÖG olan öğrencilerin akıcı okuma ve okuduğunu anlama becerilerindeki performanslarının TGG akranlarının performansları ile karşılaştırılarak incelenmesi ve her iki beceri arasındaki ilişki düzeyinin belirlenmesi amaçlanmıştır. Çalışmadan elde edilen bulguların akıcı okuma ve okuduğunu anlama arasındaki ilişkiyi ve düzeyini tanımlamak açısından ilgili alanyazına, konuya ilişkin farkındalığı artırarak ve öğretmenlere materyal ve yöntem seçimlerinde yön göstererek uygulamalara önemli katkı sağlayacağı düşünülmektedir. Bu amaç doğrultusunda aşağıdaki sorulara yanıt aranmıştır: 

BECERILLERI ARASINDAKİ İLİSKININ İNCELENMESİ

1. ÖG olan öğrenciler akıcı okuma (doğru okuma, hız, prozodi) ve okuduğunu anlama becerilerindeki performansları TGG akranlarının performanslarından anlamlı bir şekilde farklılaşmakta mıdır?

2. ÖG olan öğrencilerde akıcı okuma (doğruluk, hız ve prozodi) ve okuduğunu anlama becerileri arasındaki ilişki ne düzeydedir?

3. TGG öğrencilerde akıcı okuma (doğruluk, hız ve prozodi) ve okuduğunu anlama becerileri arasındaki ilişki ne düzeydedir?

\section{Yöntem}

\section{Araștırma Modeli}

Çalışmada nicel araştırma yöntemlerinden ilişkisel tarama modeli kullanılmıştır. Genel tarama modellerinden biri olan ilişkisel tarama modelinde, iki ve daha fazla değiş̧en arasındaki birlikte değişimin varlı̆ğ ve düzeyi belirlenmeye çalışılmaktadır. İlişkisel tarama modeli, karşılaştırma ve korelasyonel olmak üzere iki türlü yolla elde edilen ilişkilerdir. Karşılaş̧tırma türü ilişskilerde, bağımsız değiş̧kene göre oluşturulan gruplar arasında bağımlı değişkene göre anlamlı bir farklılaşma olup olmadığı incelenirken, korelasyonel türü ilişsilerde ise değişkenlerin birlikte değiş̧ip değişmedikleri veya hangi yönde bir değişme gösterdikleri belirlenmeye çalışılmaktadır (Karasar, 2011). Bu çalışma kapsamında hem karşılaştırma hem de korelasyonel türü ilişkiler incelenmiştir. Araştırmanın bağımsız değişkenleri olarak grupların ÖG ve TGG olma durumu, bağımlı değişkenleri olarak da akıcı okuma (doğruluk, hız, prozodi) ve okuduğunu anlama kullanılmıştır.

\section{Çalışma Grubu}

Araştırmanın çalışma grubunu, Ankara ilinin merkez ilçelerinde bulunan ilkokulların dördüncü sınıflarında öğrenim gören 27'si ÖG grubu, 28'i ise TGG grubu toplam 55 öğrenci oluşturmuştur. Araştırmada dört ilçedeki toplam 13 okuldan seçkisiz atama yöntemiyle veri toplanmıştır. Yenimahalle ilçesinden 13, Keçiören ilçesinden 14, Mamak ilçesinden 14 ve Çankaya ilçesinden 14 öğrenci katılımcı olarak araştırmada yer almıştır. ÖG grubunda yer alan öğrenciler ÖG tanısı almış, ek yetersizliği olmayan, ilkokulların kaynaştırma programlarına devam eden ve destek eğitim hizmetlerinden faydalanan ögrenciler arasından seçilmiş̧ir. Bu grupta yer alan öğrencilerin 10 'u kız, 17'si erkektir. TGG grubunda $\left(\bar{X}_{\mathrm{TGG}}=9.88, S S_{\mathrm{TGG}}=.42\right)$ yer alan öğrenciler ise ÖG grubundaki $\left(\bar{X}_{\mathrm{O} G}=10, S S_{\ddot{O} G}=.28\right)$ öğrencilerle aynı sınıfa devam eden, cinsiyet ve yaş açısından eşleştirilen öğrenciler arasından seçilmiştir. Bu öğrencilerin öğretmenleri tarafından herhangi bir yetersizliği olmadığı ve ortalama başarı düzeyine sahip oldukları belirtilmiştir. TGG grubunda yer alan öğrencilerin 11'i kız 17'si erkektir. Çalışmada yer alan tüm öğrencilerin uzun süreli okul devamsızlığı bulunmamaktadır.

\section{Veri Toplama Araçları}

\section{Okuma Akıcılı̆̆ını Değerlendirme Formu}

Çalışmada yer alan öğrencilerin akıcı okuma becerilerini değerlendirilmesinde, Başaran (2013) tarafından geliştirilen "Mantarlar" isimli metin yazardan izin alınarak kullanılmıştır. Metinde yer alan cümleler ortalama sekiz sözcükten oluşmaktadır. Metin öyküleyici türdedir ve iki küçük kızın mantar topladıktan sonra yaşadıkları korkulu bir olayı anlatmaktadır.

\section{Prozodik Okuma Rubriği}

Zutell ve Rasinski'nin (1991) geliştirdiği ve Yıldırım ve diğerlerinin (2011) Türkçe’ye uyarladığı rubrik, okumanın ifade ve ses düzeyi, anlam üniteleri ve tonlama, pürüzsüzlük ve hız boyutları olarak toplam dört boyutu içermektedir (Akyol vd., 2014). Her bir boyutta öğrencinin performansı 4'lü dereceleme ile değerlendirilmiştir. Öğrencinin rubrikten alabileceği en düşük puan 4 iken, en yüksek puan 16'dır. Öğrencinin almış olduğu 10'un altındaki puanlar okuyucunun prozodik okuma sorunları olduğunu; 10'un üzerindeki puanlar okuyucunun sorunu olmadığını, puanın artması ise prozodik okuma açısından başarılı olduğunu göstermektedir.

\section{Okuduğunu Anlama Değerlendirme Formu}

Çalışmada yer alan öğrencilerin okuduğunu anlama becerilerini değerlendirmek üzere Başaran (2013) tarafından dördüncü sınıf düzeyinde geliştirilmiş "Kasabanın Kahramanı" isimli metin ve bu metne ilişkin 15 okuduğunu anlama sorusu kullanılmıştır. Kasabanın Kahramanı adlı metin 336 sözcükten oluşmaktadır. Okuduğunu anlama soruları ise metinde sunulan bilgileri hatırlamaya yönelik yani yüzeysel $5 \mathrm{~N} 1 \mathrm{~K}$ sorularıdır. Öğrenciler doğru yanıtladıkları sorıular için 1, yanlış yanıtladıkları veya yanıtlayamadıkları sorular için ise 0 puan almaktadır. Aracın geliştirilmesi sürecinde uzman görüşünden yararlanılarak kapsam geçerliliği sağlanmıştır. 

BECERILERİ ARASINDAKİ İLIŞKINININ İNCELENMESİ

\section{Okuduğunu Anlama Değerlendirme Testi}

Öğrencilerin okuduğunu anlama becerileri yine Başaran (2013) tarafından geliştirilmiş 20 soruluk çoktan seçmeli sorulardan oluşan bir okuduğunu anlama testi ile de değerlendirilmiş̧ir. Test, okuduğunu anlamaya yönelik 15'i paragraf düzeyinde beşi de neden-sonuç, karşılaştırma, çıkarım, sözcük anlamı ve noktalama ile ilgili olan sorulardan oluşmuştur. Öğrencilerden formdaki paragraf sorularını okuması ve altta yer alan çoktan seçmeli yanıtlardan doğru olanı işaretlemeleri istenmiştir. Doğru olan yanıtlar "1", yanlış olan yanıtlar "0" olarak değerlendirilmiştir. Testin 141 öğrenci ile yapılan geçerlik güvenirlik çalışmaları sonucunda testin madde ayırıcılık düzeyinin .42 ile .87 arasında değiştiği, ortalama .43 ile ortalama güçlükte olduğu, KR20 iç tutarlılık değerinin ise .85 olduğu belirlenmiştir (Başaran, 2013).

\section{Uygulama Süreci}

Araştırma için uygulamalar, çocukların devam ettiği okullarda okul yönetimi tarafından belirlenen sessiz bir ortamda, birebir görüşme ile tek bir oturumda gerçekleştirilmiştir. Değerlendirme öncesi ortam havalandırılmış, veri toplama araçları değerlendirmenin yapılacağı masada hazır bulundurulmuştur. Değerlendirmeye başlamadan önce, araştırmacı öğrenciyle tanışmış, iki-üç dakika sohbet etmiştir. Değerlendirme öncesi gerçekleştirilen bu kısa sohbet, ögrencinin kendisini daha rahat hissetmesine yardımcı olmak amacıyla yapılmıştır.

Öğrencilere ilk olarak okuma akıcılı̆̆ı becerilerinin değerlendirilmesi için "Mantarlar" adlı metin verilmiştir. Öğrenciye metnin kopyası gösterilerek "Şimdi seninle 'Mantarlar' adlı güzel bir hikâye okuyacağız. Bu hikâyeyi en güzel okumanla, ara vermeden olabildiğince hızlı okumanı istiyorum. Daha sonra tekrar dinleyebilmek için okumanı kaydedeceğim. Hazır olduğunda bana 'hazırım' diyebilirsin. Ben başla dediğimde okumaya başlayacaksın. Tamam mı?" denilmiş ve öğrenci "Hazırım." dediğinde araştırmacı öğrenciye "Başla." diye yönerge vermiştir. Öğrenci metnin ilk sözcüğünü okur okumaz kronometre çalıștırılmıştır. Öğrencinin okuması ses kayılt cihazı ile kaydedilmiştir. Öğrenci metindeki herhangi bir sözcüğü beş saniye içinde okuyamadığında, araştırmacı bir sonraki sözcüğü işaret ederek devam etmesini istemiş̧tir. Araştırmacı tarafından okunan bu sözcük, araştırmacı önünde bulunan değerlendirme formuna hata olarak işaretlenmiştir. Kronometre ile ayarlanan süre sona erdiğinde, öğrencinin okuduğu son sözcüğe işaret konulmuş ve öğrencinin metni tamamlamasına izin verilmiştir. Araştırmacı da çocuğun okumasını takip ettiği süreç içerisinde kendi önündeki kayıt formuna öğrencinin yaptığı hataları ve bir dakikada okuduğu sözcük sayısını işaretlemiştir. Bu sırada, değerlendirme formuna öğrencinin bir dakikada doğru okuduğu sözcük sayısı kaydedilmiş̧tir. Aynı zamanda, öğrencinin yanlış okuduğu sözcüklerin altı çizilmiştir. Bunun sonucunda ses kaydı da alınan öğrencinin okuma hataları, dakikada okuduğu doğru sözcük sayısı belirlenmiştir.

Başaran (2013) çalışmasında bir süreç olarak okumayı TGG öğrencilerde geçerliği ve güvenirliği sağlanmış dört farklı ölçme aracıyla değerlendirmiştir. Bu çalışmada boşluk doldurma ve derinlemesine anlam kurma becerilerini ölçen açık uçlu soruların olduğu okuduğunu anlama ölçme araçları ÖG olan öğrenciler için uygun bulunmadığından dolayı kullanılmamıştır. Akıcı okumaya ilişkin veriler toplandıktan sonra okuduğunu anlamanın değerlendirilmesi için "Kasabanın Kahramanı" adlı metin verilerek öğrencilerden bu metni iki kez sessiz okumaları istenmiștir. Akıcı okumada sorunlarının okuduğunu anlamayı da olumsuz etkileyeceği düşünüldüğünden öğrencilerden metni iki kez okumaları istenmiştir (Fuchs vd., 2001). Araştırmada kullanılan okuduğunu anlama becerisini değerlendiren birinci ölçme aracı metinde doğrudan verilen bilgilerin ne kadar hatırlandığını ölçen, bilgi basamağında bulunan 15 adet kısa yanıtlı soruları içermektedir. Öğrencilerin metindeki soruları herhangi bir süre kısıtlaması olmaksızın iki kez okumalarının ardından metne ilişkin soruları yanıtlamaları istenmiştir. Öğrenci kendisini hazır hissettiğinde soruları yanıtlamaya başlamıştır. Soruların yanıtlanması tamamladığında ihtiyaç duyduğu gözlemlenen öğrencilerle 5-10 dakika ara verilmiş ve eğlenceli bir sohbet gerçekleştirilmiştir. Öğrencilerin sorulara verdiği doğru yanıtlara 1, yanlış yanıtlara ise 0 verilerek puanlandırma yapılmıştır. Ardından hem yüzeysel hem de derinlemesine anlam kurmayı değerlendiren 20 soruluk çoktan seçmeli testin uygulamasına geçilmiştir. Bu testin uygulanmasında ise öğrencilerden süre kısıtlaması olmaksızın soruları yanıtlamaları istenmiştir. Uygulama süreci kapsamında tanımlanan değerlendirme araçları uygulanıp değerlendirme işlemleri bitirildikten sonra çalışmaya katıldığı için öğrenciye teşekkür edilmiş ve öğrenci sınıfına götürülmüştür.

Uygulamalar tamamlandıktan sonra öğrencilerin okuma doğrulukları, okuma hızları, okuma prozodileri ve okuduğunu anlama performansları değerlendirilmiştir. Öğrencilerin "Mantarlar" metnindeki performansı okuma doğruluğu, akıcıllğı ve prozodi açısından değerlendirilmiştir. Okuma doğruluğu, metinde doğru okunan sözcük sayısının toplam sözcük sayısına bölünmesi ve sonucun yüz ile çarpılmasıyla elde edilmiştir. Okuma hızı ise, öğrencinin 1 dakikada okuduğu doğru sözcük sayısı belirlenerek hesaplanmıştır. Sesli okumaların prozodik 

BECERILLERI ARASINDAKİ İLİSKININ İNCELENMESİ

özellikleri ise ses kayıtları üzerinden, "Prozodik Okuma Rubriğine” göre değerlendirilmiştir. Okuduğunu anlama performanslarında soru formları incelenerek her bir doğru yanıta 1, yanlış yanıta 0 puan verilerek okuduğunu anlama puanları elde edilmiştir. Araştırmada okuduğunu anlama performans puanı, kullanılan iki testin puanlarının toplamı alınarak belirlenmiştir.

\section{Güvenirlik Hesaplamaları}

Bu çalışmada, okuma doğruluğu ve hızı, prozodik okuma ve okuduğunu anlama performanslarına ilişkin gözlemciler arası güvenirlik hesaplamaları yapılmıştır. Gözlemciler arası güvenirliğin tüm oturumların en az \%20'si incelenerek hesaplanması gerektiği belirtilmektedir (Tekin-İftar, 2018). Bu süreçte, özel eğitim alanında doktoraya devam eden bir uzman, katılımcıların ses kayıtlarından rastgele seçilen 16'sından (\%25) elde edilen verileri yeniden değerlendirmiştir. Gözlemciler arası güvenirlik, gözlemciler arası görüş birliğinin, gözlemciler arası görüş birliği ve gözlemciler arası görüş ayrılığı toplamına bölünüp yüzdesinin alınması ile hesaplanır (görüş birliği / görüş birliği + görüş ayrılığı x 100). Gözlemciler arası güvenirlik katsayısının \%80 olması yeterli kabul edilirken, $\% 90$ ve üzeri ideal güvenirlik katsayısı olarak belirtilmektedir (Tekin \& Kırcaali-İftar, 2001). Gözlemciler arası güvenirliğin doğru okuma için $\% 85$, hız için $\% 85$, prozodi için $\% 80$, okuduğunu anlama için ise $\% 100$ olduğu bulunmuştur. Bulunan bu sonuçlar, gözlemciler arası güvenirliğin kabul edilebilir düzeyde olduğunu göstermektedir.

\section{Verilerin Analizi}

Araştırmadan elde edilen veriler SPSS 18.00 paket programı kullanılarak analiz edilmiştir. Analizlerde öncelikle grupların puanlarının normallik varsayımını karşılayıp karşılamadığı test edilmiştir. Buna göre gruplardaki öğrenci sayısı 28 'den küçük olduğu için normallik Shapiro Wilk testi ile değerlendirilmiştir. Testin sonuçlarına göre (Tablo 1) her iki gruptaki öğrencilerin doğru okuma (Çarpıklık = -.62 [ÖG], -1.99 [TGG]; Basıklık = -.21 [ÖG], 4.67 [TGG]) ve prozodi puanlarının (Çarpıklık = -1.02 [ÖG], .34 [TGG]; Basıklık = 1.36 [ÖG], -1.47 [TGG]) normal dağılıma sahip olmadığı $(p<.05)$ görülmüştür (Büyüköztürk, 2012). Araştırmanın birinci sorusuna yönelik olarak grup karşılaştırmaları için normallik varsayımı sağlanmadığı için Mann WhitneyU Testi kullanılmıştır.

Grup karşılaştırmalarında etki büyüklüğünü incelemek üzere Fritz ve diğerlerinin (2012) belirttiği formül $(r=\mathrm{z} / \sqrt{ } \mathrm{N})$ kullanılmıştır. Hesaplanan etki büyüklükleri .5 ise yüksek, .3 ise orta ve .1 ise düşük olarak değerlendirilmiştir. Çalışmanın ikinci ve üçüncü araştırma soruları için ÖG ve TGG öğrencilerin akıcı okuma) ve okuduğunu anlama becerileri arasındaki ilişki grupların değişkenlerdeki puan dağılımları normal olmadığı için için Spearman Brown Sıra Farkları korelasyon katsayısı $(p)$ ile incelenmiştir.

\section{Bulgular}

\section{Grupların Akıcı Okuma ve Okuduğunu Anlama Performanslarının Karşılaştırılmasına İlişkin Bulgular}

Grupların akıcı okuma ve okuduğunu anlama performanslarına ilişkin betimsel istatistikler Tablo 1'de gösterilmektedir. Tablo 1 incelendiğinde doğru okuma, hız, prozodi ve okuduğunu anlama performanslarının puan ortalamaları incelendiğinde ÖG olan öğrencilerin TGG olan öğrencilere göre daha düşük puanlar aldıkları görülmektedir. Diğer yandan, grupların performans farklılıklarının anlamlı olup olmadığının belirlenmesi için Mann Whitney-U testi kullanılmıştır. Elde edilen veriler Tablo 2'de özetlenmiştir. Tablo 2'de görüldüğü gibi grupların doğru okuma, hız, prozodi ve okuduğunu anlama performans düzeyleri arasında anlamlı farklılıklar bulunmuştur $(p<.05)$. Sira ortalamaları ÖG olan öğrencilerin doğru okuma, hız, prozodi ve okuduğu anlamada TGG akranlarına göre daha düşük performans gösterdiğini göstermektedir. Gruplar arasındaki farkların etki büyüklükleri incelendiğinde hız, prozodi ve okuduğunu anlama değişkenlerinde gruplar arasındaki farkların etki büyüklerinin yüksek (sırasıyla $.55, .67, .58$ ), doğru okumada ise orta düzeyde olduğu (.41) görülmektedir. 

BECERILERİ ARASINDAKİ İLIŞKINIIN İNCELENMESİ

Tablo 1

Araştırmaya Katılan Grupların Akıcılık ve Okuduğunu Anlama Performanslarına İlişkin Betimsel İstatistikler

\begin{tabular}{lcccccccc}
\hline \multicolumn{1}{c}{ Değişkenler } & Grup & $n$ & $\bar{X}$ & $S S$ & Min & Max & Çarpıklık & Basılkk \\
\hline Doğru okuma & ÖG & 27 & 90.26 & 6.31 & 76 & 98 & -.62 & -.21 \\
& TGG & 28 & 95.25 & 3.89 & 82 & 100 & -1.99 & 4.67 \\
Hız & ÖG & 27 & 65.63 & 24.74 & 15 & 108 & -.06 & -.95 \\
\multirow{4}{*}{ Prozodi } & TGG & 28 & 95.32 & 16.14 & 72 & 133 & .56 & -.39 \\
& ÖG & 27 & 9.74 & 2.10 & 4 & 13 & -1.02 & 1.36 \\
Okuduğunu anlama & TGG & 28 & 13.29 & 1.88 & 11 & 16 & .34 & -1.47 \\
& ÖG & 27 & 13.15 & 5.75 & 4 & 28 & .86 & .39 \\
& TGG & 28 & 21.50 & 5.90 & 9 & 32 & -.42 & -.53 \\
\hline
\end{tabular}

Tablo 2

Araştırmaya Katılan Öğrenci Gruplarının Akıcı Okuma ve Okuduğunu Anlama Performanslarının Karşılaştırılması

\begin{tabular}{|c|c|c|c|c|c|c|c|}
\hline Değişkenler & Grup & $n$ & Sira ort. & Sira toplamı & $U$ & $p$ & $E B(r)$ \\
\hline Doğru okuma & $\begin{array}{l}\text { ÖG } \\
\text { TGG }\end{array}$ & $\begin{array}{l}27 \\
28\end{array}$ & $\begin{array}{l}21.28 \\
34.48\end{array}$ & $\begin{array}{l}574.50 \\
965.50\end{array}$ & 196.50 & .002 & .41 \\
\hline $\mathrm{H} 1 \mathrm{z}$ & $\begin{array}{l}\text { ÖG } \\
\text { TGG }\end{array}$ & $\begin{array}{l}27 \\
28\end{array}$ & $\begin{array}{l}19.19 \\
36.50\end{array}$ & $\begin{array}{c}518.00 \\
1022.00\end{array}$ & 140.00 & .000 & .55 \\
\hline Prozodi & $\begin{array}{l}\text { ÖG } \\
\text { TGG }\end{array}$ & $\begin{array}{l}27 \\
28\end{array}$ & $\begin{array}{l}16.69 \\
38.91\end{array}$ & $\begin{array}{c}450.50 \\
1089.50\end{array}$ & 72.50 & .000 & .67 \\
\hline Okuduğunu anlama & $\begin{array}{l}\text { ÖG } \\
\text { TGG }\end{array}$ & $\begin{array}{l}27 \\
28 \\
\end{array}$ & $\begin{array}{l}18.44 \\
37.21\end{array}$ & $\begin{array}{c}498.00 \\
1042.00\end{array}$ & 120.00 & .000 & .58 \\
\hline
\end{tabular}

ÖG Olan Öğrencilerde Okuma Akıcılığı ve Okuduğunu Anlama Becerileri Arasındaki İlişkilere Ait Bulgular

ÖG olan öğrencilerde okuma akıcılığı ve okuduğunu anlama performansları arasındaki ilişki Spearman Brown Sıra Farkları Katsayısı kullanılarak incelenmiştir. Elde edilen sonuçlar Tablo 3'te sunulmuştur. Tablo 3'e göre ÖG olan öğrencilerde okuduğunu anlama ile hız performansları arasında pozitif yönlü orta düzeyde anlamlı bir ilişki (.42) olduğu, buna karşın okuduğunu anlama ile doğru okuma ve prozodi arasında anlamlı bir ilişki olmadığı görülmektedir.

Tablo 3

ÖG Olan Öğrencilerde Okuma Akıcılı̆̆ı ve Okuduğunu Anlama Performansları Arasındaki İlişki

\begin{tabular}{cccc}
\hline Değişken & Okuma akıcılığı & Korelasyon katsayısı & $p$ \\
\hline \multirow{3}{*}{ Okuduğunu anlama } & Doğru okuma & .06 & .78 \\
& Hız & .42 & .03 \\
& Prozodi & .04 & .81 \\
\hline
\end{tabular}

\section{TGG Öğrencilerde Okuma Akıcılığı ve Okuduğunu Anlama Becerileri Arasındaki İlişkilere Ait Bulgular}

TGG öğrencilerin okuma akıcılığı ve okuduğunu anlama performansları arasındaki ilișkiler de Spearman Brown Sira Farkları Katsayısı kullanılarak incelenmiştir. Elde edilen sonuçlar Tablo 4'te sunulmuştur. Tablo 4'e göre TGG öğrencilerde okuduğunu anlama ile prozodi arasında pozitif yönlü orta düzeyde anlamlı bir ilişki (.63) bulunmuştur. Buna karşın öğrencilerin okuduğunu anlama ile doğru okuma ve hız performansları arasında anlamlı bir ilişki bulunmamıştır.

Tablo 4

TGG Olan Öğrencilerde Okuma Akıcılı̆̆ı ile Okuduğunu Anlama Performansları Arasındaki İlişki

\begin{tabular}{cccc}
\hline Değişken & Okuma akıcılı̆̆ & Korelasyon katsayıs1 & $p$ \\
\hline \multirow{3}{*}{ Okuduğunu anlama } & Doğru okuma & .36 & .06 \\
& Hiz & .34 & .08 \\
& Prozodi & .63 & .00 \\
\hline
\end{tabular}



BECERILERİ ARASINDAKİ İLIȘKININ İNCELENMESI

\section{Tartışma}

Bu araştırmada ilk olarak, ÖG olan ve TGG öğrencilerin akıcı okuma becerileri (doğru okuma, hız, prozodi) ve okuduğunu anlama performansları karşılaştırılmıştır. Yapılan analizler sonucunda, ÖG olan öğrencilerin tüm alanlarda TGG öğrencilerden daha düşük performans gösterdikleri belirlenmiştir. Farklara ilişkin etki büyüklükleri ise ÖG olan öğrencilerin hız (.55), prozodi (.67) ve okuduğunu anlama (.58) becerilerinde orta düzeyde bulunan etki büyüklüğü değerleriyle TGG akranlarından farklılaştığını ortaya koymaktadır. Araştırmada ayrıca öğrencilerin okuduğunu anlama becerileri ile akıcı okuma becerileri arasındaki ilişkiler incelenmiştir. ÖG olan öğrencilerde akıcı okuma becerilerinden sadece okuma hızlarının okuduğunu anlama performansları ile orta düzeyde ilişkili olduğu, TGG öğrencilerde ise sadece prozodik okumanın okuduğunu anlama ile orta düzeyde ilişkili olduğu bulunmuştur. ÖG olan öğrencilerin güçlük yaşadıkları alanlara ilişkin bulgular ÖG olan öğrencilerin performans düzeylerini göstermesi bakımından önemli olarak değerlendirilmektedir ve önceki araştırma sonuçları ile uyumludur (Alves vd., 2014; Beech \& Awaida, 1992; Erden vd., 2002; Ergül, 2012; Gökçe-Sarıpınar \& Erden, 2010; Jenkins vd., 2003; Seçkin-Yılmaz \& Bayd1k, 2017; Tobia \& Marzocchi, 2014).

Araştırma bulguları incelendiğinde, ÖG olan öğrencilerin TGG akranlarına göre verilen metni okurken daha fazla hata yaptıkları ve bu temelde belirlenen okuma doğruluk oranlarının ise daha düşük olduğu görülmüştür. Her iki grubun doğru okuma performansına bakıldığında, ÖG grubunun metni \%90 doğrulukla öğretimsel düzeyin en alt sınırında, TGG grubun ise \%95 doğrulukla bağımsız düzeyde okuduğu belirlenmiştir. Mercer ve Mercer (2005) tarafından belirtilen okuma doğruluk oranları temelinde ÖG grubunun endişe düzeyine oldukça yakın bir performansa sahip olduğu görülmektedir. Bu sonuca göre, ÖG olan öğrencilerin çok fazla sayıda okuma hatası yaptıkları ve bu nedenle öğretim desteğine gereksinim duydukları söylenebilir. Elde edilen bu bulgu önceki araştırma sonuçlarıyla uyumludur (Baydık, 2012; Erden vd., 2002; Ergül, 2012; Gökçe-Sarıpınar \& Erden, 2010; Jenkins vd., 2003; Kochnower vd., 1983; Seçkin-Yılmaz \& Baydık, 2017).Yapılan çok sayıda çalışmada da ÖG olan öğrencilerin okurken çok fazla hata yaptıkları, endişe düzeyinde okudukları ve akranlarından yaklaşık iki ya da iki buçuk yıl geriden okudukları belirtilmiştir (Baydık, 2012; Erden vd., 2002; Ergül, 2012; Gökçe-Sarıpınar \& Erden, 2010; Jenkins vd., 2003; Kochnower vd., 1983; Seçkin-Yılmaz \& Baydık, 2017). Bu bağlamda, araştırmada yer alan ÖG olan öğrencilerin okuma doğruluğu performanslarının arttırılmasına yönelik müdahale programlarının geliştirilmesi gerektiği düşünülmektedir.

Doğru çözümleme becerileri daha üst düzey okuma becerileri için temel oluşturmaktadır (Adlof vd., 2006; Amendum vd., 2015; Garcia \& Cain, 2014; Jenkins vd., 2003; Klauda \& Guthrie, 2008). Sözcükleri çözümleyemeyen yani doğru okuyamayan bir öğrenci hızlı ve prozodik okuma yapamamakta ve okuduğunu anlayamamaktadır (Allor \& Chard, 2011; Klauda \& Guthrie, 2008; Kuhn, 2004). Öğrencilerin doğru okumada yaşadığı problemlerin özellikle sesbilgisel işlemleme becerilerindeki (sesbilgisel farkındalık, hızlı otomatik isimlendirme ve sesbilgisel kısa süreli bellek) zorluklarla ilişkili olduğu belirtilmiştir (López \& González, 1999). Sesbilgisel işlemleme becerilerinde yaşanan sorunlar nedeniyle ÖG olan öğrencilerin yeni karşılaştıkları sözcükleri çözümlemede de güçlük yaşadıkları ve bu nedenle bütünsel okuma aşamasına geçmede, otomatik ve hızlı okumada da sorunlar yaşadıkları belirtilmektedir (Allor \& Chard, 2011; Baydık, 2002; López \& González, 1999; Seçkin-Yılmaz \& Baydık, 2017). Bu durumun, okuduğunu anlamayı olumsuz etkilemesinin yanı sıra okuma deneyimlerini azalttığı ve dil becerilerini de (sözcük dağarcığı ve dilbilgisi vb.) olumsuz etkilediği belirtilmektedir (Allor \& Chard, 2011; Baydık, 2002; Seçkin-Yılmaz \& Baydık, 2017). Dolayısıyla bu öğrencilerle yapılacak olan çalışmalarda da özellikle sesbilgisel farkındalık becerilerindeki performans düzeylerinin incelenmesi gerektiği ve buna uygun olarak da sesbilgisel farkındalık becerilerinin geliştirilmesine yönelik müdahalelerle okuma öğretim sürecinin desteklenmesi gerektiği düşünülmektedir.

Grupların okuma hızı performanslarının değerlendirilmesi sonucunda ÖG olan öğrencilerin dakikada ortalama 65 sözcük okudukları bulunurken TGG öğrencilerin dakikada ortalama 95 sözcük okudukları belirlenmiştir. Bu ortalamalara bakıldığında, ÖG olan öğrencilere ilişkin 65 sözcüğün hem Türkiye'de dördüncü sınıflar için belirlenmiş okuma hızı normlarının (97-99 sözcük) hem de TGG öğrencilerin ortalamalarının oldukça altında olduğu görülmektedir. ÖG grubunda yer alan öğrencilerin bir dakikalık okuma hızı performanslarına bakıldığında 15 ila 108, NGG öğrencilerin ise 72 ila 133 sözcük arasında değiştiği görülmüştür. Türkiye'de öğrencilerin okuma hızlarına ilişkin sınıf düzeyinde belirlenen bazı normlara göre dördüncü sınıf öğrencilerinin 97-99 sözcük okumaları beklenmektedir. Dolayısıyla bu normlara göre TGG öğrencilerin okuma hızlarının sınıf düzeyi için belirlenmiş normlara uygun olduğu görülürken ÖG olan öğrencilerin elde ettiği ortalama okuma hızının bu normlar çerçevesinde birinci ve ikinci sınıf düzeyinde olduğu dikkati çekmektedir. Norm çalışmalarında birinci sınıflar için belirlenen ortalama okuma hızları birinci sınıflar için 45/48 ikinci sınıf için 73/75'dir (Erden vd., 2002; Gökçe-Sarıpınar \& Erden, 2010). Bu kapsamda ÖG olan öğrencilerin okuma hızlarının yaklaşık 2.5 yıl geride 

BECERILLERI ARASINDAKİ İLİSKININ İNCELENMESİ

olduğu görülmektedir. Elde edilen bu bulgu ÖG olan öğrencilerin bir veya üç yıl geride olduklarını gösteren diğer çalışma sonuçlarıyla uyumludur (Ergül, 2012; Gökçe-Sarıpınar \& Erden, 2010; Güzel-Özmen, 2005; Jenkins vd., 2003; Seçkin-Yılmaz \& Baydık, 2017; Tobia \& Marzocchi, 2014).

Öğrencilerin okuma doğruluğunda göstermiş olduğu performans düzeyleri göz önünde bulundurulduğunda akıcı okumadaki düşük performanslarının da beklendik bir bulgu olduğu düşünülmektedir. Çözümlemede başarısız olan bir öğrencinin akıcı okuması çok mümkün olmamaktadır (Perfetti, 1982). ÖG olan öğrencilerin bu düzeydeki okuma performanslarının dikkatle değerlendirilmesi gerektiği açıktır. Gökçe-Sarıpınar ve Erden (2010) yaptıkları çalışmada öğrencilerin sınıf düzeyi arttıkça okuma hızının da arttığını ve bu durumun hem olgunlaşma hem de süreç içerisinde okuma deneyiminin artmasıyla ilgili olabileceğini ifade etmişlerdir. Araştırmada yer alan öğrencilerin dördüncü sınıfta olmalarına rağmen, okuma problemlerine bağlı olarak okuma deneyimlerinin de sınırlı olduğu ve düşük okuma performanslarının bu sinırlılıktan da etkilendiği düşünülmektedir. Bu açıdan, okuma hızının geliştirilmesine yönelik müdahale programları uygulanmalı, okuma deneyimleri arttırılmalı ve öğrencilerin bu becerideki gelişimleri yakından takip edilmelidir. Özellikle, okuma hızı ile okuduğunu anlama arasındaki anlamlı ve orta düzeydeki ilişkiler göz önünde bulundurulduğunda okuma hızının geliştirilmesine yönelik müdahale programlarının sıklığının ve yoğunluğunun arttırılmasının önemli olacağı düşünülmektedir. Özetle, müdahale programlarında, çözümleme becerisine temel oluşturan sesbilgisel farkındalık becerilerinin ve okuma deneyiminin sıklığının ve yoğunluğunun arttırılmasının öğrencilerin hem okuma hızı hem de okuduğunu anlama becerilerine katkıda bulunacağı düşünülmektedir.

Araştırmada grupların prozodik okumada performansları karşılaştırılmış ve elde edilen sonuçlar ÖG olan öğrencilerin akranlarına göre anlamlı olarak daha düşük puanlar elde ettiklerini göstermiştir. Her iki grubun prozodi puan ortalamalarına bakıldığında, ÖG grubunun 9.74 puan, TGG grubun ise 13.29 puan elde ettikleri görülmüştür. Araştırmada kullanılan prozodi rubriğine göre 10'un altındaki puanlar okuyucunun prozodik okumada güçlük yaşadığını; 10'un üzerindeki puanlar okuyucunun artan şekilde okumalarında daha prozodik özellikler sergilediği şeklinde ifade edilmektedir (Baydık, 2012). Buna göre, ÖG grubunun prozodik okumada sorunları olduğu TGG grubun ise prozodik okumada daha başarılı oldukları sonucuna varılmıştır. Çalışmada elde edilen veriler betimsel olarak incelendiğinde prozodide en düşük puanı alan öğrencilerin diğer tüm alanlarda da düşük puan aldıkları görülmüştür. Prozodik okumanın okuduğunu anlama ile ilişkisindeki önemi göz önünde bulundurulduğunda prozodik okuma özelliklerinin düşük olmasının okuduğunu anlamayı olumsuz yönde etkileyeceği düşünülmektedir (Therrien, 2004). Bu nedenle, akıcı okuma öğretimlerinin sadece otomatik sözcük tanıma becerilerine odaklanması yerine aynı zamanda okumada ifade ve ritim becerilerini kapsayan prozodi becerilerine de odaklanması gerekmektedir. Öğrenciler sözcük çözümlemede ilerleyip otomatikleşme düzeyine ulaştıklarında, bilişsel kaynaklarını çözümledikleri sözcüklerin anlamına daha çok ayırabilmekte ve böylelikle metindeki cümleleri uygun ifade ve hız ile okuyabilmektedirler (Allinder vd., 2001; LaBerge \& Samuels, 1974; Schreiber, 1991). Ülkemizde ilköğretim sınıflarında prozodik okumaya ilişkin ne tür öğretim yöntemlerinin ve müdahale programlarının kullanıldığı hakkında ya da ne düzeyde önem verildiği hakkında soru işaretleri bulunmaktadır. Ancak bu çalışmadan elde edilen sonuçlara göre ÖG olan öğrencilerin yaşamış oldukları prozodik okumaya ilişkin zorlukların değerlendirilmesi ve okuma öğretiminde prozodik okumanın geliştirilmesine yönelik çalışmaların yapılmasının önemli olacağı düşünülmektedir.

Çalışmada grupların okuduğunu anlama performansları da karşılaştırılmış ve ÖG olan öğrencilerin TGG akranlarına göre anlamlı olarak daha düşük performans gösterdikleri belirlenmiştir. Ortalama puanlarının ÖG olan grupta 13.15 TGG grupta ise 21.50 puan olduğu görülmüştür. ÖG olan öğrencilerin okuduğunu anlamadaki düşük performanslarının öğrencilerin okuma doğruluğu, hız ve prozodide göstermiş oldukları düşük performans nedeniyle beklendik bir bulgu olduğu düşünülmektedir. Çok sayıda çalışmada da ÖG olan öğrencilerin okuduğunu anlama performanslarının sınıf düzeyinin gerisinde olduğu ve bu nedenle de özellikle dördüncü sınıf ile başlayan diğer akademik alanlardaki öğrenmeyi gerçekleştiremedikleri ifade edilmektedir (Baydık, 2011; Chall, 1987). Her ne kadar okuduğunu anlama performansını etkileyen bellek, alıcı ve ifade edici sözcük bilgisi ve bilişsel ve üstbilişsel strateji kullanımı gibi diğer süreçler söz konusu olsa da okuma doğruluğu ve akıcılığının okuduğunu anlamada ön koşul beceriler olduğu sıklıkla ifade edilmektedir (Baydık, 2006; Baydık, 2011; Botsas \& Padeliadu, 2003; Cain \& Oakhill, 2006). Dolayısıyla okuduğunu anlamada yaşanan başarısızlığa temel olan doğruluk, hız ve prozodiye ilişkin problemli durumlar söz konusu ise bunların ayrıntılı olarak değerlendirilmesi ve öğrencilerin bu temel süreçlerde yaşadıkları problemlere yönelik müdahaleler yapılması önemlidir. Akıcı okumaya ek olarak okuduğunu anlamayı etkileyen diğer becerilerin incelenmesi, değerlendirilmesi ve uygun müdahale programlarının uygulanması okuduğunu anlama performansının artırılması için gereklidir. 

BECERILLERI ARASINDAKİ İLİSKININ İNCELENMESİ

Araştırmada akıcı okuma becerileri ve okuduğunu anlama performansları arasındaki ilişkiler ÖG ve TGG öğrenciler için ayrı ayrı incelenmiştir. ÖG olan öğrencilerde okuduğunu anlama ile hız arasında orta düzeyde anlamlı bir ilişki bulunurken okuduğunu anlama ile doğru okuma ve prozodi performansları arasında anlamlı bir ilişki bulunmamıştır. İlgili alanyazında, bir metnin uygun hızda okunmasının okuduğunu anlama için önemli ve gerekli olduğunu destekleyen birçok çalışma bulunmaktadır (Adams, 1990; Fuchs vd., 2009; Klauda \& Guthrie, 2008; Kuhn \& Stahl, 2003; Logan, 1997; Ribeiro vd., 2016; Schwanenflugel vd., 2004). Bu nedenle, ÖG olan öğrencilerde hız ile okuduğunu anlama arasında ilişki bulunması özellikle TGG öğrenciler ile yapılan çalışmaların sonuçları bağlamında beklendik bir bulgudur (Brown vd., 1986; Coşkun, 2002; Hudson vd., 2005; Kuhn \& Stahl, 2003; Lai vd., 2014; Wong vd., 2008; Torgesen vd., 2001). Okuma hızı, anlama için temel bir süreçtir (Calet vd., 2015; Garcia \& Cain, 2014; Hook \& Jones, 2002; Rasinski, vd., 2016). Sözcük tanıma süreçleri yeterince akıc1 olduğunda (otomatiklik), öğrenci bilişsel kapasitesini metni anlamaya, metinle ilgili düşünceler geliştirmeye ve metnin detaylarına inmeye harcayabilecektir (Nathan \& Stanovich, 1991). Bu açıdan değerlendirildiğinde, ÖG olan öğrenciler için yavaş okumanın okuduğunu anlama başarısını olumsuz yönde etkilediği çalışmalarda da ortak bulgudur (Breznitz, 1987; Hook \& Jones, 2002; Rasinski vd., 2016). Okuma güçlüğü olan bireylerin sözcükleri yavaş okuması okuduğunu anlamasını olumsuz etkilediği gibi okuma deneyimlerini azaltır dolayısıyla okumanın dil ve bilişsel becerilere (sözcük dağarcığı, sözdizimi bilgisi vb.) olan katkısından yoksun bırakır (Baydık, 2012). Kısacası, öğrencinin sözcükleri doğru ve akıcı okuyamaması anlamasını etkiler ve daha az okumasına neden olur bu durum da onun bilişsel ve dil becerilerinin gelişimini olumsuz yönde etkiler.

TGG öğrencilerde ise okuduğunu anlama ile sadece prozodi arasında orta düzeyde anlamlı bir ilişki bulunmuştur. TGG öğrencilerde okuduğunu anlamanın sadece prozodik okuma ile ilişkili bulunması alanyazında bildirilen bulgular ile uyumlu olarak değerlendirilmektedir (Calet vd., 2015; Kuhn \& Stahl, 2003; Miller \& Schwanenflugel, 2008; Rasinski vd., 2009; Schwanenflugel vd., 2004). Birçok kaynakta akıcı okumanın anlama ile ilişkisi en çok prozodi becerisine dayandırılmaktadır (Alves vd., 2014; Başaran, 2013; Baştuğ \& Akyol, 2012; Benjamin \& Schwanenflugel, 2010; Kuhn \& Stahl, 2003; Kuhn vd., 2010; Miller \& Schwanenflugel, 2008; Veenendaal vd., 2015). Ülkemizde yapılan çalışmalarda da TGG öğrencilerde akıcı okuma becerilerinin tümü arasında okuduğunu anlama ile en yüksek ilişkiyi gösteren becerinin prozodi olduğu belirtilmiştir (Başaran, 2012; Baştuğ \& Akyol, 2012; Baştuğ \& Keskin, 2012). Bu araştırmalarda okuma hızından daha üst düzey bir beceri olarak ifade edilen prozodinin akıcı okumanın da en temel becerisi olduğu ortaya atılmıştır. Baştuğ ve Keskin (2012) prozodinin anlamanın farklı düzeyleri ile en güçlü ilişkiyi gösteren akıcı okuma becerisi olduğunu belirttikleri çalışmada bu durumun prozodik okuma becerisinin daha gelişmiş bir okumayı içermesinden dolayı anlamanın niteliğini arttıran becerilerin doğru okuma ve prozodi olduğunu, hız becerisinin okuma düzeyinin belirlenmesinde etkili ve gerekli olduğunu fakat anlama açısından önceliğinin daha sınırlı olduğu şeklinde yorumlamışlardır. Tipik gelişim gösteren dördüncü sınıf öğrencilerle yapılan bir çalışmada ise okuma hızı ile okuduğunu anlama ilişkisinin düşük olduğu gösterilmiştir. Öğrencilerin büyük bir kısmında akıcı okuma olmasına rağmen okuduğunu anlama puanlarının ranjının oldukça geniş olduğunu belirten Başaran (2013) bu durumu, yavaş okumanın anlamada sorun yaratabileceği ancak okuma hızını arttırmanın anlamayı da arttırmada temel faktör olmadığı şeklinde ifade etmiştir. Özet olarak, çalışma kapsamında TGG öğrenciler için elde edilen bulguların önceki çalışmalar ile tutarlı olduğu gözlenmiştir.

Diğer yandan, Calet ve diğerleri (2015) çalışmalarında, dördüncü sınıflarda prozodi ile anlama ilişkisinin, ikinci sınıflara göre daha yüksek olduğunu bulmuşlardır. Yazarlara göre, öğrencilerin okumada otomatiklik becerisinde yeterli olmalarından sonra artık daha zor metinleri okumaları ve anlamaları beklenmektedir. Bu sebeple, öğrenciler metni anlamak için okumada doğruluk, hız bileşenlerinin yanı sıra prozodi bileşenine de gereksinim duymaktadırlar. Prozodik okuma, okuduğunu anlama becerisini anlamsal ve sözdizimsel farkındalık ile desteklemektedir. Dolayısıyla, ikinci sınıf öğrencilerinin prozodik okuma açısından dördüncü sınıf öğrencilerine göre daha sınırlı deneyime sahip olmalarının prozodik okuma becerilerinin okuduğunu anlama becerileri ile daha düşük düzeyde ilişkili olmasına temel oluşturabileceği ifade edilmektedir. Bu doğrultuda bakıldığında, birinci ve ikinci sınıf düzeyinde performans gösteren ÖG olan öğrencilerde okuduğunu anlama becerilerinin sadece hız ile ilişkili olması, TGG olan öğrencilerde ise diğer becerilere oranla daha üst düzey bir beceri olan prozodinin okuduğunu anlama ile ilişkili bulunmasının beklenen bir sonuç olduğu söylenebilir.

Öğrenciler okuma hızları arttıkça anlama daha çok odaklanmakta ve böylelikle daha uygun prozodi ile okuyabilmektedir (Calet vd., 2015; Seçkin-Yılmaz \& Baydık, 2017). Diğer taraftan, öğrencinin uygun prozodi ile okuduğu için mi daha iyi anladığ1 yoksa daha iyi anladığ 1 için mi uygun bir prozodi ile okuduğu hala tam olarak açıklanabilmiş değildir (Miller \& Schwanenflugel, 2008; Seçkin-Yılmaz \& Baydık, 2017). Bu açıdan, öğrencilerin 

BECERILERİ ARASINDAKİ İLIŞKININ İNCELENMESİ

okuduğunu anlama becerilerinin geliştirilmesine yönelik müdahale programlarının kapsamına prozodik okuma desteğinin de eklenmesinin istendik sonuçların elde edilmesine önemli ölçüde katkı sunacağı düşünülmektedir.

Sonuç olarak, bu araştırmada ÖG olan öğrencilerin hem akıcı okuma hem de okuduğunu anlamada akranlarının önemli ölçüde gerisinde oldukları ve bu becerilerinin geliştirilmesi gerektiği belirlenmiştir. Öğrenme güçlüğü olan öğrencilerin değerlendirilen tüm becerilerde TGG akranlarına göre daha düşük performans göstermiş olmaları, bu öğrencilerin özel eğitim destek hizmetlerinden faydalanan çocuklar olması göz önünde bulundurulduğunda dikkatle değerlendirilmesi gereken bir bulgu olduğu düşünülmektedir. Bu durum, çocuklara uygulanan müdahale programlarının yetersizliğini göstermektedir. Oysa akranlarının okuma becerilerinde önemli derecede ilerlediği ve öğretimin diğer akademik alanlardaki öğrenmeye daha çok odaklandığı dördüncü sınıfta yaşadıkları bu okuma problemlerinin daha sonraki yıllarda yaşanacak akademik başarısızlıklara neden olacağı kaçınılmazdır (Baydık, 2011; Ergül, 2012). Bu açıdan, ÖG öğrencilere yönelik uygulanacak müdahale programlarında uygun değişikliklerin yapılması ve yoğunluğunun arttırılması önemli olacaktır. Bununla ilgili olarak öğretmenlere sunulacak ÖG olan öğrenciler ve öğretim programları hakkında hizmet içi eğitimlerin sağlanması ve öğrencilerin güçlükleri ile ilgili öğretmenlere daha fazla bilgi verilmesi son derece önemlidir.

\section{Sinırlılıklar ve Öneriler}

Araştırma Ankara ilinde dördüncü sınıfa devam eden, Rehberlik ve Araştırma Merkezi incelemeleri sonucunda ÖG tanısı alan ve aynı sınıfa devam eden TGG 55 öğrenci ile sınırlandırılmıştır. Çalışmada sadece okuduğunu anlamanın akıcı okuma becerileri ile olan ilişkisi değerlendirilmiş ve sınırlı düzeyde ilişki bulunmuştur. Elde edilecek sonuçların genellenebilmesi için farklı bölgelerden ve okullardan seçilen daha büyük öğrenci gruplarıyla benzer araştırmalar yapılması önerilmektedir. Buna ek olarak, çalışma sadece dördüncü sınıf düzeyinde gerçekleştirilmiştir. Akıcılık ve okuduğunu anlama becerilerinin daha küçük yaşlarda veya daha sonraki yaşlarda nasıl bir gelişimsel süreç izlediği incelenmemiştir. Dolayısıyla, ileride yapılacak olan çalışmaların farklı sınıf düzeyleri ve stratejilerle tekrarlanması önerilmektedir. Erken yaştan itibaren yapılan araştırma sonuçları ile ÖG olan öğrencilerin nasıl bir gelişimsel süreç izledikleri hakkında daha detaylı bilgi edinilebilir. Böylelikle, erken müdahale ve destek eğitim programlarının da gelişimi hakkında bilgi elde etmek mümkündür.

İleride yapılacak araştırmalara yönelik olarak, akıcı okuma ve okuduğunu anlama becerilerini etkileyen dil ve bilişsel beceriler bulunmaktadır. Okuma sürecinin merkezinde olan sesbilgisel işlemleme becerileri (sesbilgisel farkındalık, sesbilgisel kısa süreli bellek, hızlı otomatik isimlendirme) ve ilişkili olduğu sözel dil (sözcük bilgisi, biçimbilim/morfoloji, semantik/anlambilim, sentaks/sözdizimi, kullanım/pragmatik) ve bilişsel (çalışma belleği, yürütücü işlev becerileri, üstbilişsel strateji kullanımı) becerilerin birlikte senkronize bir şekilde kullanımını gerektiren çalışmalara uygun müdahale programlarına yer verilmesi önerilmektedir (López \& González, 1999; Snowling vd., 2003). Bu becerilerin bazıları okumanın çözümleme aşamasına, bazıları anlama aşamasına, bazıları ise hem çözümleme hem de anlama aşamasına doğrudan katkı sağlamaktadır. Dolayısıyla okuyucuların bireysel gereksinimlerine göre hem dil hem de okuma alanını destekleyen müdahale programlarının uygulanabilmesi önemlidir. Değerlendirme ve müdahale çalışmalarının sayılarının yaş gruplarına göre arttırılması gerektiği ve bu becerilerin yukarıda belirtilen dil ve bilişsel becerilerle olan ilişkisi de eklenerek kapsamlı bir şekilde ele alınması gerektiği düşünülmektedir.

\section{Yazarların Katkı Düzeyleri}

Çalışma konusu, yüksek lisans tez çalışması kapsamında birinci yazar tarafından belirlenmiştir. Çalışmanın raporlanması (araştırma deseni, veri toplama ve verilerin analizi) sürecine ise aynı zamanda birinci yazarın yüksek lisans tez danışmanı olan Prof. Dr. Cevriye Ergül tarafından destek verilmiştir. 


\section{Kaynaklar}

Adams, M. J. (1990). Beginning to read: Thinking and learning about print. MIT Press.

Adlof, S. M., Catts, H. W., \& Little, T. D. (2006). Should the simple view of reading include a fluency component? Reading and Writing, 19(9), 933-958. https://doi.org/10.1007/s11145-006-9024-z

Afflerbach, P., Pearson, P. D., \& Paris, S. G. (2008). Clarifying differences between reading skills and reading strategies. The Reading Teacher, 61(5), 364-373. https://doi.org/10.1598/RT.61.5.1

Akyol, H., \& Kodan, H. (2016). Okuma güçlüğünün giderilmesine yönelik bir uygulama: Akıcı okuma stratejilerinin kullanımı [A Practice for eliminating reading difficulty: The use of fluent reading strategies]. Ondokuz Mayı Üniversitesi Eğitim Fakültesi Dergisi, 35(2), 7-21. https://dergipark.org.tr/tr/pub/omuefd/issue/26853/282414

Akyol, H., Yıldırım, K., Ateş, S., Çetinkaya, Ç., \& Rasinski, V. T. (2014). Okumayı değerlendirme: Öğretmenler için kolay ve pratik bir yol [Evaluation of reading: An easy and practical way for teachers] (1. bask1). Pegem Akademi.

Allinder, M. R., Dunse, L., Brunken, D. C., \& Obermiller-Krolikowski, J. H. (2001). Improving fluency in at-risk students with learning disabilities. Remedial and Special Education, 22(1), 48-54. https://doi.org/10.1177/074193250102200106

Allor, H. J., \& Chard, J. D. (2011). A comprehensive approach to improving reading fluency for students with disabilities. Focus on Exceptional Children, 43(5), 1-12. https://doi.org/10.17161/foec.v43i5.6909

Alves, M. L., Reis, C., \& Pinheiro, A. (2014). Prosody and reading in dyslexic children. Dyslexia, 21(1), 35-49. https://doi.org/10.1002/dys.1485

Amendum, J. S., Conradi, K., \& Liebfreund, D. M. (2015). The push for more challenging texts: An analysis of early readers's rate, accuracy and comprehension. Reading Psychology, 37(4), 570-600. https://doi.org/10.1080/02702711.2015.1072609

American Psychiatric Association. (2013). Diagnostic and statistical manual of mental disorders (5th ed.). American Psychiatric Publishing.

Amerikan Psikiyatri Birliği. (2014). Ruhsal bozuklukların tanısal ve sayımsal el kitabı (5. baskı) [Diagnostic and statistical manual of mental disorders (5th ed.)] (E. Köroğlu, Çev. ed.). Hekimler Yayın Birliği. (Orijinal kitabın yayın tarihi 2013).

Anastasiou, D., \& Griva, E. (2009). Awareness of reading strategy use and reading comprehension among poor and good readers. Ilköğretim https://dergipark.org.tr/tr/pub/ilkonline/issue/8598/107014

Ateş, S., \& Yıldız, M. (2011). Okumayı farklı yöntemlerle öğrenen ilköğretim üçüncü sınıf öğrencilerinin sesli okuma akıcılıklarının karşılaştırılması [Comparison of reading fluency of third grade students who learned reading with different models]. Türk Eğitim Dergisi, 9(1), 101-124. https://dergipark.org.tr/tr/pub/tebd/issue/26101/275010

Bahap-Kudret, Z., \& Baydık, B. (2016). Başarılı ve başarısız dördüncü sınıf okuyucularının okuduğunu anlama ve özetleme becerileri [Reading comprehension and summarizing skills of successful and unsuccessful fourth grade readers]. Ankara Üniversitesi Eğitim Bilimleri Fakültesi Özel Ĕgitim Dergisi, 17(3), 317 346. https://doi.org/10.21565/ozelegitimdergisi.268558

Başaran, M. (2013). Okuduğunu anlamanın bir göstergesi olarak akıcı okuma [Reading fluency as an indicator of reading comprehension]. Kuram ve Uygulamada Eğitim Bilimleri, 13(4), 2277-2290. https://idealonline.com.tr/IdealOnline/lookAtPublications/paperDetail.xhtml?uId=658

Baştuğ, M., \& Akyol, H. (2012). Akıcı okuma becerilerinin okuduğunu anlamayı yordama düzeyi [The level of prediction of reading comprehension by fluent reading skills]. Kuramsal Ë̆itimbilim Dergisi, 5(4), 394411. https://dergipark.org.tr/tr/pub/akukeg/issue/29347/314043 

BECERILLERI ARASINDAKİ İLİSKININ İNCELENMESİ

Baştuğ, M., \& Keskin, H. K. (2012). Akıcı okuma becerileri ile anlama düzeyleri (basit ve çıkarımsal) arasındaki ilişki [The relationship between fluent reading skills and comprehension level (literal and inferential)]. Ahi Evran Üniversitesi Eğitim Fakültesi Dergisi, 13(3), 227-244. https://dergipark.org.tr/tr/pub/kefad/issue/59486/854943

Baydık, B. (2002). Okuma güçlüğü olan ve olmayan öğrencilerin sözcük okuma becerilerinin karşılaştırılması [Comparison of the word reading skills of children with and without reading disability] (Tez Numaras1: 122517) [Doktora tezi, Ankara Üniversitesi]. Yüksek Öğretim Kurulu Ulusal Tez Merkezi.

Baydık, B. (2006). Okuma güçlüğü olan çocukların sözcük okuma becerileri [Word reading skills of children with reading difficulties]. Ankara Üniversitesi Eğitim Bilimleri Fakültesi Özel Eğitim Dergisi, 7(1), 29-36. https://doi.org/10.1501/ozlegt 0000000097

Baydık, B. (2011). Okuma güçlüğü olan öğrencilerin üstbilişsel okuma stratejilerini kullanımı ve öğretmenlerinin okuduğunu anlama öğretim uygulamalarının incelenmesi [Examining the use of metacognitive reading strategies of students with reading difficulties and their teachers' reading comprehension instruction $\begin{array}{lllll}\text { practices]. } & \text { Eğitim } & \text { Bilim, } & 36(162), & 319 .\end{array}$ http://egitimvebilim.ted.org.tr/index.php/EB/article/view/1354

Baydık, B. (2012). Okuma güçlükleri. S. S. Yıldırım-Doğru (Ed.), Öğrenme güçlükleri [Learning difficulties] içinde (ss. 131-166). Eğiten Kitap.

Beech, R. J., \& Awaida, M. (1992). Lexical and nonlexical routes: A comparison between normally achieving and poor readers. Journal of Learning Disabilities, 25(3), 196-206. https://doi.org/10.1177/002221949202500307

Benjamin, G. R., \& Schwanenflugel, J. P. (2010). Text complexity and oral reading prosody in young readers. Reading Research Quarterly, 45(4), 388-404. https://doi.org/10.1598/rrq.45.4.2

Botsas, G., \& Padeliadu, S. (2003). Goal orientation and reading comprehension strategy use among students with and without reading difficulties. International Journal of Educational Research, 39(4-5), 477-495. https://doi.org/10.1016/j.ijer.2004.06.010

Breznitz, Z. (1987). Increasing first graders' reading accuracy and comprehension by accelerating their reading rates. Journal of Educational Psychology, 79(3), 236-242. https://doi.org/10.1037/0022-0663.79.3.236

Brown, A. L., Palincsar, A. S., \& Purcell, L. (1986). Poor readers: Teach, don't label. In U. Neisser (Ed.), The school achievement of minority children: New perspectives (1st ed., pp. 105-143). Lawrence Erlbaum Associates.

Bursuck, W., \& Damer, M. (2007). Reading instruction for students who are at risk or have disabilities. Pearson Education Inc.

Büyüköztürk, Ş. (2012). Sosyal bilimler için veri analizi el kitabı [Data analysis manual for social sciences] (16. bask1). Pegem Akademi.

Cain, K., \& Oakhill, J. (2006). Profiles of children with specific reading comprehension difficulties. British Journal of Educational Psychology, 76(4), 683-696. https://doi.org/10.1348/000709905x67610

Calet, N., Defior, S., \& Palma, G. N. (2015). A cross-sectional study of fluency and reading comprehension in Spanish primary school children. Journal of Research in Reading, 38(3), 272-285. https://doi.org/10.1111/1467-9817.12019

Chall, J. (1987). Reading development in adults. Annals of Dyslexia, 37(1), $240-251$. https://doi.org/10.1007/bf02648070

Coşkun, E. (2002). Okumanın hayatımızdaki yeri ve okuma sürecinin oluşumu [The position of reading in our lives and its formation process about reading]. Tübar, 11, 231-244. https://dergipark.org.tr/tr/pub/tubar/issue/16952/176982

Çaycı, B., \& Demir, K. M. (2006). Okuma ve anlama sorunu olan öğrenciler üzerine karşılaştırmalı bir çalışma [A comparative study on students' reading and comprehension problems]. Türk Eğitim Bilimleri Dergisi, 4(4), 437-456. https://dergipark.org.tr/tr/pub/tebd/issue/26118/275152 

BECERILLERI ARASINDAKİ İLİSKININ İNCELENMESİ

Çeliktürk-Sezgin, Z., \& Akyol, H. (2015). Okuma güçlüğü olan dördüncü sınıf öğrencisinin okuma becerilerinin geliştirilmesi [Improving reading skills of fourth grade elemantary student who has reading disability]. Türkçe Eğitimi Araştırma Makalesi, 4(2), 4-16. https://doi.org/10.19128/turje.181115

Doğanay-Bilgi, A. (2017). Öğrenme güçlüğü hakkında temel bilgiler ve uygulamalar. E. R. Özmen (Ed.), Okuma yazmada ögretimsel stratejiler [Instructional strategies in literacy] içinde (ss. 1-23). Eğiten Kitap.

Dowhower, S. L. (1991). Speaking of prosody: Fluency's unattended bedfellow. Theory into Practice, 30(3), 165175. https://doi.org/10.1080/00405849109543497

Dündar, H., \& Akyol, H. (2014). Okuma ve anlama problemlerinin tespiti ve giderilmesine ilişkin örnek olay çalışması [A case study regarding definition and solution of reading and comprehensive problems]. Ë̆itim ve Bilim, 39(171), 361-377. http://egitimvebilim.ted.org.tr/index.php/EB/article/view/1991

Edmonds, S. M., Vaughn, S., Wexler, J., Reutebuch, C., Cable, A., Tackett, K. K., \& Schnakenberg, W. J. (2009). A synthesis of reading interventions and effects on reading comprehension outcomes for older struggling readers. Review of Educational Research, 79(1), 262-300. https://doi.org/10.3102/0034654308325998

Erden, G., Kurdoğlu, F., \& Uslu, R. (2002). İlköğretim okullarına devam eden Türk çocuklarının sınıf düzeylerine göre okuma hızı ve yazım hataları normlarının geliştirilmesi [Development of grade level norms for reading speed and writing errors of Turkish elementary school children]. Türk Psikiyatri Dergisi, 13(1), 5-13. https://psycnet.apa.org/record/2002-12610-001

Ergül, C. (2012). Okumada güçlük yaşayan öğrencilerin okuma performanslarının öğrenme güçlügü riski açısından değerlendirilmesi [Evaluation of reading performances of students with reading problems for the risk of learning disabilities]. Kuram ve Uygulamada Ĕgitim Bilimleri Dergisi, 12(3), 2033-2057. https://www.idealonline.com.tr/IdealOnline/lookAtPublications/paperDetail.xhtml?uId=1835

Fırat, T., \& Ergül, C. (2020). 3D strateji öğretiminin öğrenme güçlüğü olan öğrencilerin bilişsel ve üstbilişsel stratejileri kazanmalarına etkisi [The effect of TWA strategy instruction on students with learning disabilities developing cognitive and metacognitive strategies]. Kastamonu Eğitim Dergisi, 28(3), 13901406. https://doi.org/10.24106/kefdergi.4025

Fritz, C. O., Morris, P. E., \& Richler, J. J. (2012). "Effect size estimates: Current use, calculations, and interpretation": Correction to Fritz et al. (2011). Journal of Experimental Psychology: General, 141(1), 30. https://doi.org/10.1037/a0026092

Fuchs, S. L., Fuchs, D., Hosp, K. M., \& Jenkins, R. J. (2001). Oral reading fluency as an indicator of reading competence: A theoretical, empirical, and historical analysis. Scientific Studies of Reading, 5(3), 239256. https://doi.org/10.4324/9781410608246-3

Garcia, R. J., \& Cain, K. (2014). Decoding and reading comprehension: A meta-analysis to identify which reader and assessment characteristics influence the strenght of the relationship in english. Review of Educational Research, 84(1), 74-111. https://doi.org/10.3102/0034654313499616

Gökçe-Sarıpınar, E., \& Erden, G. (2010). Okuma güçlüğünde akademik beceri ve duyusal-motor işlevleri değerlendirme testlerinin kullanılabilirliği [Usability of tests measuring academic skills and sensorymotor functions in reading disability]. Türk Psikoloji Dergisi, 25(65), 56-66. https://www.psikolog.org.tr/tr/yayinlar/dergiler/1031828/tpd1300443320100000m000110.pdf

Güldenoğlu, B., Kargın, T., Gengeç, H., \& Gürbüz, M. (2019). Okuma sürecinde dil temelli becerilerin önemi: Dil-okuma ilişkisine yönelik bulgular [The importance of language-based skills in the reading process: Evidence from the language-reading relationship]. Turkish Journal of Special Education, 1(1), 1-27. https://doi.org/10.37233/TRSPED.2009.0101

Güzel-Özmen, R. (2005). Öğrenme güçlüğü olan öğrencilerin okuma hızlarının metinlerde karşılaştırılması [Comparisons of the reading speeds of the students with learning difficulties through texts]. Ĕgitim ve Bilim Dergisi, 30(136), 25-30. http://egitimvebilim.ted.org.tr/index.php/EB/article/view/5189

Harwell, J. M. (2001). Learning disabilities handbook: Ready-to-use strategies and activities for teaching students with learning disabilities. Jossey-Bass. 

BECERILLERI ARASINDAKİ İLİSKININ İNCELENMESİ

Hitchcock, C. H., Prater, M. A., \& Dowrick, P. W. (2004). Reading comprehension and fluency: Examining the effects of tutoring and video self-modeling on first-grade students with reading difficulties. Learning Disability Quarterly, 27(2), 89-103. https://doi.org/10.2307/1593644

Hook, P. E., \& Jones, S. D. (2002). The importance of automaticity and fluency for efficient reading comprehension. Perspectives, 28(1), 9-14. https://eps.schoolspecialty.com/EPS/media/SiteResources/downloads/articles/importance_automaticity_fluency.pdf

Hudson, R. F., Lane, H. B., \& Pullen, P. C. (2005). Reading fluency assessment and instruction: What, why, and how? The Reading Teacher, 58(8), 702-714. https://doi.org/10.1598/rt.58.8.1

İnce-Cora, N. (2007). Zihinsel engelli ögrencilere okuduğunu anlama becerilerinin ögrretilmesinde işbirlikli ögrenme yaklaşımı ile sunulan ögretim programının etkililiğinin incelenmesi [Doktora Tezi, Ankara Üniversitesi]. http://hdl.handle.net/20.500.12575/34120

Jenkins, J. R., Fuchs, L. S., Broek, P., Espin, C., \& Deno, S. L. (2003). Accuracy and fluency in list and context reading of skilled and RD groups: Absolute and relative performance levels. Learning Disabilities Research and Practice, 18(4), 237-245. https://doi.org/10.1111/1540-5826.00078

Juul, H., Poulsen, M., \& Elbro, C. (2014). Separating speed from accuracy in beginning reading development. Journal of Educational Psychology, 106(4), 1096-1106. https://doi.org/10.1037/a0037100

Karasar, N. (2011). Bilimsel araştırma yöntemi [Scientific research method] (22. bask1). Nobel Yayınevi.

Karasu, H. P., Girgin, Ü., \& Uzuner, Y. (2011). İşitme engelli öğrenciler ve işiten öğrencilerin okuma hatalarının hata analizi ile değerlendirilmesi [Evaluation of hearing impaired and normal hearing students' reading miscues by miscue analysis]. İönü Üniversitesi Ĕ̆itim Fakültesi Dergisi, 12(3), 79-96. https://dergipark.org.tr/tr/pub/inuefd/issue/8698/108633

Karatay, H. (2009). Okuma stratejileri bilişsel farkındalık ölçeği [A metacognitive awareness inventory of reading strategies]. Abant İzet Baysal Sosyal Bilimler Enstitüsü Dergisi, 2(19), 58-80. https://dergipark.org.tr/en/download/article-file/154655

Kendeou, P., Van den Broek, P., Helder, A., \& Karlsson, J. (2014). A cognitive view of reading comprehension: Implications for reading difficulties. Learning Disabilities Research and Practice, 29(1), 10-16. https://doi.org/10.1111/ldrp.12025

Keskinkılıç, K., \& Keskinkılıç, S. B. (2005). Türkçe'nin temel becerileri ve ses temelli cümle yöntemi ile ilk okuma yazma ögretimi [The basic skills of Turkish and first literacy teaching with phonic based sentence method]. Asil Yayınevi.

Kim, Y. S., Wagner, R. K., \& Lopez, D. (2012). Developmental relations between reading fluency and reading comprehension: A longitudinal study from grade 1 to grade 2. Journal of Experimental Child Psychology 113(1), 93-111. https://doi.org/10.1016/j.jecp.2012.03.002

Klauda, S. L., \& Guthrie, J. T. (2008). Relationships of three components of reading fluency to reading comprehension. Journal of Educational Psychology, 100(2), 310-321. https://doi.org/10.1037/0022$\underline{0663.100 .2 .310}$

Kocaarslan, M. (2019). İyi ve zayıf okuyucular için okuduğunu anlama: Kuramsal ve ampirik açıdan bir bakış [Reading comprehension for good and poor readers: An overview of theoretical and empirical perspective]. Ankara Üniversitesi Ë̆itim Bilimleri Fakültesi Özel Eğitim Dergisi, 20(2), 396-393. https://doi.org/10.21565/ozelegitimdergisi.433448

Kochnower, J., Richardson, E., \& DiBenedetto, B. (1983). A comparison of the phonic decoding ability of normal and learning disabled children. Journal of Learning Disabilities, 16(6), 348-351. https://doi.org/10.1177/002221948301600609

Kuhn, M. (2004). Helping students become accurate, expressive readers: Fluency instruction for small groups. International Reading Association, 58(4), 338-344. https://doi.org/10.1598/rt.58.4.3

Kuhn, M. R., \& Stahl, S. A. (2003). Fluency: A review of developmental and remedial practices. Journal of Educational Psychology, 95(1), 3-21. https://doi.org/10.1037/0022-0663.95.1.3 

BECERILERİ ARASINDAKİ İLIŞKININ İNCELENMESİ

Kuhn, M. R., Schwanenflugel, P. J., Meisinger, E. B., Levy, B. A., \& Rasinski, T. V. (2010). Aligning theory and assessment of reading fluency: Automaticity, prosody and definitions of fluency. Reading Researh Quarterly, 45(2), 230-251. https://doi.org/10.1598/rrq.45.2.4

LaBerge, D., \& Samuels, S. J. (1974). Toward a theory of automatic information processing in reading. Cognitive Psychology, 6(2), 293-323. https://doi.org/10.1016/0010-0285(74)90015-2

Lai, S. A., George-Benjamin, R., Schwanenflugel, P. J., \& Kuhn, M. R. (2014). The longitudinal relationship between reading fluency and reading comprehension skills in second-grade children. Reading-Writing Quarterly, 30(2), 116-138. https://doi.org/10.1080/10573569.2013.789785

Lerner, J. W. (2000). Learning disabilities: Theories, diagnosis, and correction. Houghton Mifflin.

Logan, G. D. (1997). Automaticity and reading: Perspectives from the instance theory of automatization. Reading and Writing Quarterly, 13(2), 123-146. https://doi.org/10.1080/1057356970130203

López, M. R., \& González, J. E. J. (1999). An analysis of the word naming errors of normal readers and reading disabled children in Spanish. Journal of Research in Reading, 22(2), 180-197. https://doi.org/10.1111/1467-9817.00081

Malone, L. D., \& Mastropieri, M. A. (1992). Reading comprehension instruction: Summarization and selfmonitoring training for students with learning disabilities. Exceptional Children, 58(3), 270-279. https://doi.org/10.1177/001440299105800309

McConnaughhay, M. C. (2008). The relationship between reading fluency and reading comprehension for thirdgrade students [Master's thesis, Goucher College]. https://www.academia.edu/31309664

Mercer, C. D., \& Mercer, A. R. (2005). Teaching students with learning problems (7th ed.). Pearson-MerrillPrentice Hall.

Mercer, C. D., \& Pullen, P. C. (2005). Students with learning disabilities (7th ed.). Merrill-Prentice Hall.

Miller, J., \& Schwanenflugel, P. J. (2008). A longitudinal study of the development of reading prosody as a dimension of oral reading fluency in early elementary school children. Reading Research Quarterly, 43(4), 336-354. https://doi.org/10.1598/rrq.43.4.2

Nathan, R. G., \& Stanovich, K. E. (1991). The causes and consequences of differences in reading fluency. Theory Into Practice, 30(3), 176-184. https://doi.org/10.1080/00405849109543498

National Reading Panel. (2013). Teaching children to read: An evidence-based assessment of the scientific research literature on reading and its implications for reading instruction. National Institute of Child Health and Human Development.

O’Connor, R. E. (2017). Reading fluency and students with reading disabilities: How fast is fast enough to promote reading comprehension? Journal of Learning Disabilities, 51(2), 124-136. https://doi.org/10.1177/0022219417691835

Özmen, E. R. (2017). Öğrenme güçlüğü hakkında temel bilgiler ve uygulamalar [Main information and applications about learning disability]. Eğiten Kitap.

Paige, D. D., \& Lavell-Magpuri, T. (2014). Reading fluency in the middle and secondary grades. International Electronic Journal of Elemantary Education, $\quad 7(1), \quad 83-96$. https://www.iejee.com/index.php/IEJEE/article/view/66

Perfetti, C. A. (1982). Discourse context, word identification and reading ability. Advances in Psychology, 9(1), 53-61. https://doi.org/10.1016/s0166-4115(09)60040-6

Pesa, N., \& Somers, S. (2007). Improving reading comprehension through application and transfer of reading strategies [Master's thesis, Saint Xavier University]. https://eric.ed.gov/?id=ED496540

Pikulski, J. J., \& Chard, D. J. (2005). Fluency: Bridge between decoding and reading comprehension. The Reading Teacher, 58(6), 510-519. https://doi.org/10.1598/rt.58.6.2 

BECERILLERI ARASINDAKİ İLİSKININ İNCELENMESİ

Quellette, P. G. (2006). What's meaning got to do with it: The role of vocabulary in word reading and reading comprehension, Journal of Educational Psychology, 98(3), 554-566. https://doi.org/10.1037/0022$\underline{0663.98 .3 .554}$

Rasinski, T. (2006). Reading fluency instruction: Moving beyond accuracy, automaticity and prosody. The Reading Teacher, 59(7), 704-706. https://doi.org/10.1598/rt.59.7.10

Rasinski, T. V. (2012). Why reading fluency should be hot! The Reading Teacher, 65(8), 516-522. https://doi.org/10.1002/trtr.01077

Rasinski, T. V., Blachowicz, C., \& Lems, K. (2012). Fluency instruction: Research-based best practices (2nd ed.). Guilford Press.

Rasinski, T. V., Rupley, W. H., Paige, D. D., \& Nichols, W. D. (2016). Alternative text types to imrove reading fluency for competent to struggling readers. International Journal of Instruction, 9(1), 163-178. https://doi.org/10.12973/iji.2016.9113a

Rasinski, T., Rikli, A., \& Johnston, S. (2009). Reading fluency: More than automaticity? More than a concern for the primary grades? Literacy Research and Instruction, 48(4), 350-361. https://doi.org/10.1080/19388070802468715

Ribeiro, I., Cadime, I., Freitas, T., \& Viana, F. L. (2016). Beyond word recognition, fluency, and vocabulary: The influence of reasoning on reading comprehension. Australian Journal of Psychology, 68(2), 107-115. https://doi.org/10.1111/ajpy.12095

Schreiber, P. A. (1991). Understanding prosody's role in reading acquisition. Theory Into Practice, 30(3), 158164. https://doi.org/10.1080/00405849109543496

Schwanenflugel, P. J., Hamilton, A. M., Kuhn, M. R., Wisenbaker, J. M., \& Stahl, S. A. (2004). Becoming a fluent reader: Reading skill and prosodic features in the oral reading of young readers. Journal of Educational Psychology, 96(1), 119-129. https://doi.org/10.1037/0022-0663.96.1.119

Seçkin-Yılmaz, Ş., \& Baydık, B. (2017). Okuma performası düşük olan ve olmayan ilkokul öğrencilerinin okuma akıcılıkları [Reading fluency of elementary students with and without low reading performance]. Ilkögretim Online, 16(4), 1652-1671. https://doi.org/10.17051/ilkonline.2017.342983

Senate Labor and Human Resources Committee. (1997). S. Rept. 105-17 - Individuals with disabilities education act amendments of 1997. (No. S.717) https://www.congress.gov/congressional-report/105thcongress/senate-report/17

Shaywitz, S. E. (2003). Overcoming dyslexia: A new and complete science-based program for reading problems at any level. Vintage.

Snowling, M. J., Gallagher, A., \& Frith, U. (2003). Family risk of dyslexia is continuous: Individual differences in the precursors of reading skill. Child Development, 74(2), 358-373. https://doi.org/10.1111/1467$\underline{8624.7402003}$

Swanson, H. L., \& O'Connor, R. (2009). The role of working memory and fluency practice on the reading comprehension of students. Journal of Learning Disabilities, 42(6), 548-575. https://doi.org/10.1177/0022219409338742

Tankersly, K. (2003). Threads of reading: Strategies for literacy development. Association for Supervision ve Curriculum Development. ASCD.

Tekin-İftar, E. (2018). Çoklu başlama düzeyi modelleri. E. Tekin-İftar (Ed.), Eğitim ve davranış bilimlerinde tekdenekli araştırmalar [Single case researchs in education and behavioral sciences] içinde (ss. 181-254). Anı Yayıncılık.

Tekin, E., \& Kırcaali-İftar, G. (2001). Özel eğitimde yanlışsız öğretim yöntemleri [Errorless teaching methods in special education]. Nobel.

Therrien, J. W. (2004). Fluency and comprehension gains as a result of repeated reading. Remedial and Special Education, 25(4), 252-261. https://doi.org/10.1177/07419325040250040801 

BECERILLERI ARASINDAKİ İLİSKININ İNCELENMESİ

Thompson, D. R., \& L. E. Bushnell (Eds.). (2009). Reading, learning, writing and disorders. Nova Science Pub Inc.

Tobia, V., \& Marzocchi, G. M. (2014). Cognitive profiles of Italian children with developmental dyslexia. Reading Research Quarterly, 49(4), 437-452. https://doi.org/10.1002/rrq.77

Torgesen, J. K., Alexander, A. W., Wagner, R. K., Rashotte, C. A., Voeller, K. K. S., \& Conway, T. (2001). Intensive remedial instruction for children with severe reading disabilities: Immediate and long-term from two instructional approaches. Journal of Learning Disabilities, 78(34), 33-58. https://doi.org/10.1177/002221940103400104

Uzunkol, E. (2013). Akıcı okuma sürecinde karşılaşılan sorunların tespiti ve giderilmesine yönelik bir durum çalışması [A case study for identifying and overcoming the problems encountered during the fluent reading process]. Mersin Üniversitesi Eğitim Fakültesi Dergisi, 9(1), 70-83. https://dergipark.org.tr/tr/pub/mersinefd/issue/17382/181537

Veenendaal, N. J., Groen, M. A., \& Verhoeven, L., (2015). The role of speech prosody and text reading prosody in children's reading comprehension. British Journal of Educational Psychology, 84(4), 521-536. https://doi.org/10.1111/bjep.12036

Wise, J. C., Sevcik, R. A., Morris, R. D., Lovett, M. W., Wolf, M., Kuhn, M., Meisinger, B., \& Schwanenflugel, P. (2010). The relationship between different measures of oral reading fluency and reading comprehension in second-grade students who evidence different oral reading fluency difficulties. Language, Speech, and Hearing Services in Schools, 41(3), 340-348. https://pubmed.ncbi.nlm.nih.gov/20421613/

Wong, Y. L. B., Graham, L., Hoskyn, M., \& Berman, J. (2008). The ABCs of learning disabilities (2nd ed.). Elsevier Inc.

Wood, D. E. (2008). Modeling the relationship between cognitive and reading measures in third and fourth grade children. Journal of Psychoeducational Assessment, 27(2), 96-112. https://doi.org/10.1177/0734282908323609

Yıldırım, K., Yıldız, M., \& Ateş, S. (2011). Kelime bilgisi okuduğunu anlamanın anlamlı bir yordayıcısı mıdır ve yordama gücü metin türlerine göre farklılaşmakta mıdır? [Is vocabulary a strong variable predicting reading comprehension and does the prediction degree of vocabulary vary according to text types?]. Kuram ve Uygulamada Eğitim Bilimleri, $11(3), \quad 1531-1547$. http://openaccess.ahievran.edu.tr/xmlui/handle/20.500.12513/426

Zutell, J., \& Rasinski, T. V. (1991). Training teachers to attend to their students' oral reading fluency. Theory into Practice, 30(3), 211-217. https://doi.org/10.1080/00405849109543502 


\section{Ankara University Faculty of Educational Sciences Journal of Special Education}

2022, 23(2), 365-388

\title{
An Investigation of the Relationship Between Reading Fluency and Reading Comprehension in Students with and without Learning Disabilities
}

\author{
Gülperi Arabacı iD 1
}

\begin{abstract}
Introduction: The relationship between reading fluency and reading comprehension was investigated among 55 students attending $4^{\text {th }}$ grade in this study. 27 had learning disabilities and 28 were typically developing.

Method: The relational screening model, a quantitative research model, was used in data analysis. Reading accuracy, speed, and prosody skills of students were assessed using a grade level text. Comprehension was assessed using a short-answer test that measured whether the information related to the text was retained, and open-ended questions that measured skills in terms of constructing meaning both literally and in depth. The data were analyzed via SPSS 18.00.
\end{abstract}

Findings: The reading accuracy, speed, prosody, and comprehension scores of students with learning disabilities were significantly lower than those by their typically developing peers. There was a significant moderate correlation between reading speed and comprehension among students with learning disabilities. There was a significant moderate correlation between prosody and comprehension in typically developing students.

Discussion: The students with learning disability scored lower in both reading fluency and reading comprehension. They were significantly behind their peers. It is inevitable that these reading problems in the fourth grade, where reading skills are expected to be acquired to a great extent and where teaching in academic subjects instead of reading instruction is started, will cause academic failures in the later years.

Keywords: Learning disability, fluent reading, reading accuracy, reading speed, prosody, reading comprehension.

To cite: Arabac1, G. (2022). An investigation of the relationship between reading fluency and reading comprehension in students with and without learning disabilities. Ankara University Faculty of Educational Sciences Journal of Special Education, 23(2), 365-388. https://doi.org/10.21565/ozelegitimdergisi.700711

${ }^{1}$ Doctoral Student, Eskişehir Osmangazi University, E-mail: gulperiardc@ gmail.com, https://orcid.org/0000-0002-8987-9984 


\section{Introduction}

Issues with fluency and reading comprehension are the most common problems among students with learning disabilities (Bayd1k, 2012). Fluency is the ability to read a text accurately, quickly and appropriately (Bursuck \& Damer, 2007; Lai et al., 2014; Kuhn \& Stahl, 2003; Mercer \& Mercer, 2005; Tankersly, 2003). Individuals who quickly recognize words read fluently (Lerner, 2000; National Reading Panel, 2013; Wong et al., 2008). Fluency consists of three main components including accuracy, speed, and prosody (Ateş \& Y1ldız, 2011; Baştuğ \& Akyol, 2012; Bursuck \& Damer, 2007; Hudson et al., 2005; Mercer \& Pullen, 2005; Rasinski, 2006). Accuracy refers to reading the words with correct articulation in the text (Başaran, 2013). Reading accuracy includes recognizing and identifying words correctly (Baştuğ \& Akyol, 2012; Çaycı \& Demir, 2006; Dündar \& Akyol, 2014; Uzunkol, 2013). Adams (1990) states that an individual establishes a relationship between the visual stimulus with its codes and meaning in memory during word recognition process, which helps the reader articulate the word correctly. By identifying the word, the reader both articulates the words correctly and constructs their meaning (Çaycı \& Demir, 2006).

Reading speed, another component of fluency, involves the process of recognizing words fast and automatically (Nathan \& Stanovich, 1991; Rasinski, 2012). According to LaBerge and Samuels (1974), automatic reading is defined as fast, accurate and effortless word recognition in reading process. According to Rasinski et al. (2012), as the individual performs the word recognition process more easily, faster and accurately, the decoding process takes place more automatically. When reading is carried out in this way, cognitive resources could be directed to reading comprehension (Lai et al., 2014; Wong et al., 2008). Prosody is a linguistic term describing the rhythmic and intonation features of speech. Prosodic reading is the ability to read rhythmically and melodically with appropriate expression (Ateş \& Yıldız, 2011; Baştuğ \& Keskin, 2012; Dowhower, 1991). Only when decoding is fluent, prosodic reading development is possible (Schwanenflugel et al., 2004).

Reading comprehension is considered as a complex process. It is the ultimate aim of reading and a way to learn (Adams, 1990; Anastasiou \& Griva, 2009; Edmonds et al., 2009; Lai et al., 2014). Individuals learn if they can understand what they read. In this direction, the text must first be read accurately, fluently and prosodic for an effective reading comprehension (Dündar \& Akyol, 2014). The individual must recognize the words visually, decode them, as well as associate and interpret the phonological and holistic features of the words to reach the underlying meaning of the sentence (Karatay, 2009; Kendeou et al., 2014).

Previous studies examining the relationship between reading fluency and reading comprehension among students at various grade levels show that there is a significant relationship between students' performance in reading fluency and reading comprehension (Başaran, 2013; Baştuğ \& Akyol, 2012; Baştuğ \& Keskin, 2012; Hitchcock, 2012). Based on this context, the aim of this study is to examine the fluency and reading comprehension skills of $4^{\text {th }}$ grade students in comparison to the performance of their typically-developing (TD) peers and to identify the relationship between these two skills. For this purpose, answers to the three research questions were sought. Firstly, this study examined whether students with learning disability differed significantly from their peers with typical development in terms of fluent reading (accuracy, speed and prosody) and reading comprehension. For the second and third research questions of the study, the level of the relationship between fluent reading (accuracy, speed, and prosody) and reading comprehension was examined in students with learning disabilities and typical development. This study will contribute to the related literature, increase awareness on the subject, and guide teachers in the selection of materials and methods for their instructon.

\section{Method}

The relational screening model, a quantitative research design, was used in the data analysis. The study group included 55 students (27 of them had learning disabilities and 28 of them were typically developing) attending $4^{\text {th }}$ grade in the central districts in Ankara. Data was collected from a total of 13 schools in four districts. The students with learning disabilities (LD) did not have any additional disabilities, continued the mainstream programs at primary schools and received educational support. 10 of the students in this group were girls and 17 were boys. Most of them were children who received the diagnosis in the past 3 years. The students in the TD group were in the same class as the students in the LD group. They were matched in terms of gender and age. Their teachers stated that these students did not have any physical disabilities and that they were at an average achievement level. 11 of the students in the TD group were female and 17 were male. All students in this study did not have any problems with absenteeism. 
Teacher interview form, fluency assessment tool, reading comprehension assessment tool, and prosodic reading scoring key were used as data collection tools. The teacher interview form developed by the researcher was given to the teachers before the implementation to obtain information about the teachers themselves and the students. In order to assess the reading fluency skills of the students in the study, the text called "Mantarlar (Mushrooms)" consisting of 226 words developed by Başaran (2013) was used. The researcher marked the mistakes and audio-recorded the number of words read in a minute while the child was reading. In the following, the student's reading mistakes and the correct number of words per minute was determined. In order to assess reading comprehension skills of students in the study, the text developed by Başaran (2013), "Kasabanın Kahraman1 (Hero of the Town)" was used. The text consisted of 336 words at the fourth grade level and 15 reading comprehension questions. The students were asked the questions after reading the text twice. Also, a reading comprehension test consisting of 20 multiple choice questions developed by Başaran (2013) was utilized. This test contained 15 paragraph comprehension questions and five cause-effect, comparison, inference, word meaning and punctuation questions. Finally, the rubric developed by Zutell and Rasinski (1991) and adapted to Turkish by Yildirım et al. (2009) was used to assess the prosodic features of the student performances in the text entitled "Mantarlar (Mushrooms)". The rubric included four dimensions: The expression and sound level of the reading, the units of meaning and intonation, smoothness, and speed.

The data were analyzed via SPSS 18.00. Accordingly, the number of students in the groups was less than 28 , normality was evaluated by the Shapiro Wilk test. Results of the test showed that reading accuracy and prosody scores of the students in both groups did not show normality. The independent variables of the study were the status of the groups as LD and TD. The dependent variables included fluent reading (accuracy, speed, prosody) and reading comprehension. For the first research question of the study, Mann Whitney-U Test was conducted for group comparisons. In this study, differences between groups (LD and TD) were separately examined for each dependent variable by Mann Whitney-U test. In the group comparison, the formula $(r=\mathrm{z} / \sqrt{ } \mathrm{N})$ by Fritz et al. (2012) was used to examine the effect size. The calculated effect sizes were .5 as high, .3 as medium and .1 as low. For the second and third research questions of the study, as scores did not exhibit normal distribution, the relationship between reading fluency (accuracy, speed, prosody) and reading comprehension skills in LD and TD students was examined through Spearman's Rank Correlation Coefficient test.

\section{Findings}

In this study, firstly, the reading fluency (accuracy, speed, prosody) and reading comprehension performances of the LD and TD groups were descriptively examined. When the averages of the scores of both groups in terms of reading accuracy, speed, prosody and reading comprehension performances were examined, the students with LD had lower scores than students with TD. Significant differences were found between the accuracy $(U=196.50)$, speed $(U=140.00)$, prosody $(U=72.50)$ and reading comprehension $(U=120.00)$ performances. Students with LD had lower scores in terms of accuracy, speed, prosody, and reading comprehension than their TD peers. The mean score of the LD group was 21.28 for reading accuracy, 19.19 for speed, 16.69 for prosody and 18.44 for reading comprehension. All means were lower than those of the TD group, which were $34.48,36.50,38.91$ and 37.21 , respectively. The effect sizes of the differences between groups were high in accuracy, speed and reading comprehension $(.55, .67, .58$, respectively) and moderate (.41) in reading accuracy.

Spearman's Rank Correlation Coefficient results showed that there was a moderately significant relationship between reading comprehension and speed, $\left(r_{s}=.42\right)$ whereas there was no significant relationship between reading comprehension and reading accuracy, prosody for students with LD. Finally, the Spearman's Rank Correlation Coefficient results showed that a moderately significant correlation was found between reading comprehension and prosody for students with $\mathrm{LD}\left(r_{s}=.63\right)$. There was no significant relationship between reading comprehension and reading accuracy, speed in TD students.

\section{Discussion}

The reading fluency (accuracy, speed, and prosody) and reading comprehension performances of LD and TD students were compared in this study. As a result, the students with LD performed significantly lower than their peers with TD in all areas. The relationship was also examined between reading comprehension and reading fluency skills. Only the reading speed was moderately correlated with reading comprehension in students with $\mathrm{LD}$, whereas prosodic reading was moderately correlated with reading comprehension in TD students. 
Students with LD do not perform as well as their peers in terms of reading fluency and reading comprehension skills. The effect sizes related to the differences reveal that the students with LD are different from TD peers in speed, prosody and reading comprehension skills, respectively. This finding is important in terms of showing the performance levels of students with LD and is consistent with previous findings (Alves et al., 2014; Beech \& Awaida, 1992; Erden et al., 2002; Ergül, 2012; Jenkins et al., 2003; Gökçe-Sarıpınar \& Erden, 2010; Seçkin-Yılmaz \& Baydık, 2017; Tobia \& Marzocchi, 2014).

The students with LD had more mistakes in reading than their TD peers. The reading accuracy rates were lower. As a result of the accuracy evaluation of the groups, the students with LD and TD had a reading speed of 66 and 95 words per minute. The LD group read the text with $90 \%$ accuracy at the instructional level and the TD group with 95\% accuracy. Mercer and Mercer (2005) indicated that the LD group had a very close performance to the frustration level based on the reading accuracy rates. The students with LD made too many reading mistakes and needed instructional support. Programs and interventions should be developed to increase the reading accuracy performances of the students with LD.

The per-minute average of the LD students is relatively below the reading speed norms for fourth grade TD students in Turkey. These students are normally expected to read between 97-99 words per minute (Erden et al., 2002; Gökçe-Sarıpınar \& Erden, 2010). While the reading speed of TD students is in line with the norms determined for grade level, it is noteworthy that the average reading speed of the students with LD is at the first and second grade levels. The average reading speed values for the first grades are 45/48 for the first grade and 73/75 for the second grade (Erden et al., 2002; Gökçe-Sarıpınar \& Erden, 2010). In this study, the reading speed of students with LD group was about 2.5 years behind. This finding is consistent with previous studies showing that students with LD are one to three years behind their peers (Ergül, 2012; Gökçe-Sarıpınar \& Erden, 2010; Jenkins et al., 2003; Seçkin-Yılmaz \& Baydık, 2017).

The performances of the groups were compared in terms of prosodic reading. The students with LD significantly scored lower than their peers. When the prosody score averages of both groups were examined, the LD group achieved 9.74 points and the TD group achieved 13.29 points. According to the prosody rubric used in the research, the scores below 10 indicated that the reader had problems in prosodic reading. The scores above 10 indicated that the reader exhibited more prosodic features in reading. Accordingly, the LD group had problems in prosodic reading in comparison to the TD group. The students with the lowest score in prosody received low scores in all other fields. Considering the relationship between prosodic reading and reading comprehension, it is important to note the low prosodic reading scores (Therrien, 2004). When students progress in word decoding and reach the level of automation, they can further allocate their cognitive sources to the meaning of the words they decode. Thus, they can read the sentences in the text with appropriate expression and speed (Allinder et al., 2001; LaBerge \& Samuels, 1974; Schreiber, 1991). Although we do not know much about what kind of teaching methods and intervention programs are used for prosodic reading in elementary classrooms in Turkey, it will be important to evaluate the difficulties related to prosodic reading experienced by the students with LD and to carry out interventions to improve the prosodic reading of these students.

The reading comprehension performances of the groups were also compared. The students with LD had a significantly lower performance than their TD peers. The average scores were 13.15 in the LD group and 21.50 in the TD group. The poor performance of the students with LD in reading comprehension was an expected finding due to the poor performance of students' reading accuracy, speed and prosody. Previous studies state that the reading comprehension performances of students with LD are behind the grade level and they cannot perform well in other academic fields, especially when starting with the fourth grade (Bayd1k, 2011; Chall, 1987). Although there are other factors that affect comprehension such as memory, receptive and expressive vocabulary, the use of cognitive and metacognitive strategies, it is often stated that reading accuracy and fluency are the prerequisites for reading comprehension (Bayd1k, 2006; Bayd1k, 2011; Botsas \& Padeliadu, 2003; Cain \& Oakhill, 2006). Therefore, if there are problems with accuracy, speed and prosody that are the basis for the failure in reading comprehension, these areas should be evaluated in detail and the problems experienced by students in these basic processes should be eliminated. Following this, it will be appropriate to examine and evaluate other processes that affect reading comprehension and to implement appropriate intervention programs.

The relationship between reading fluency and reading comprehension was separately examined for LD and TD groups. While there was a moderately significant relationship between reading comprehension and speed for students with LD, no significant relationship was found between reading comprehension and reading accuracy and prosody. There was a moderately significant relationship between reading comprehension and prosody for 
students with TD. Previous studies support the importance of reading a text at an appropriate speed for reading comprehension (Adams, 1990; Fuchs et al., 2009; Klauda \& Guthrie, 2008; Kuhn \& Stahl, 2003; Logan, 1997; Ribeiro et al., 2016; Schwanenflugel et al., 2004). On the other hand, the relationship between reading fluency and comprehension is mostly based on prosody skills (Alves et al., 2014; Başaran, 2013; Baştuğ \& Akyol, 2012; Benjamin \& Schwanenflugel, 2010; Kuhn \& Stahl, 2003; Kuhn et al., 2010; Miller \& Schwanenflugel, 2008; Veenendaal et al., 2015).

The relationship between speed and reading comprehension for students with LD is an expected finding, especially based on the other results of studies (Brown et al., 1986; Coşkun, 2002; Hudson et al., 2005; Kuhn \& Stahl, 2003; Lai et al., 2014; Wong et al., 2008; Torgesen et al., 2001). Reading speed is a fundamental factor for comprehension (Calet et al., 2015; Garcia \& Cain, 2014; Hook \& Jones, 2002; Rasinski et al., 2016). When word recognition is fluent enough, the student will be able to use his/her cognitive capacity to understand the text, to develop thoughts about the text, and to delve into the details of the text (Nathan \& Stanovich, 1991). In this respect, slow reading negatively affects reading comprehension (Breznitz, 1987; Hook \& Jones, 2002; Rasinski et al., 2016).

The relationship between reading comprehension and prosodic reading among students with TD is widely reported by previous studies (Calet et al., 2015; Kuhn \& Stahl, 2003; Miller \& Schwanenflugel, 2008; Rasinski et al., 2009; Schwanenflugel et al., 2004). In studies conducted in Turkey, the skill that shows the highest relation with reading comprehension among all reading fluency skills is prosody (Başaran, 2012; Baştuğ \& Akyol, 2012; Baştuğ \& Keskin, 2012). In these studies, prosody is described as a higher-level skill. It is the most basic skill of reading fluency. Baştuğ and Keskin (2012) state that prosody shows the highest relationship with comprehension since prosodic reading involves a more advanced reading ability. Reading accuracy and prosody increase the quality of comprehension. In addition to this, the speed of reading is necessary but not a priority in relation to the level of comprehension. In a study with fourth-grade students with TD, the relationship between reading speed and reading comprehension was low which indicated that although the majority of students could read fluently, the range of reading comprehension scores was wide (Başaran, 2013). Therefore, slow reading may cause problems in comprehension. But, increasing reading speed is not the main factor for progress in comprehension.

As the reading speed increases, students can focus more on comprehension and read with more appropriate prosody (Calet et al., 2015; Seçkin-Yılmaz \& Baydık, 2017). On the other hand, it is still unclear whether the student comprehends better because s/he reads with appropriate prosody or vice versa (Miller \& Schwanenflugel, 2008; Seçkin-Yılmaz \& Baydık, 2017). In this respect, it is thought that the inclusion of prosodic reading support in intervention programs to improve students' reading comprehension would significantly contribute to desired outcomes.

As a result, the students with LD scored lower in both reading fluency and reading comprehension. They were significantly behind their peers. This shows the inadequacy of intervention programs for students with LD. However, it is inevitable that these reading problems in the fourth grade, where reading skills are expected to be acquired to a great extent and where teaching in academic subjects instead of reading instruction is started, will cause academic failures in the later years (Baydık, 2011; Ergül, 2012). In this respect, it will be important to make appropriate changes and increase the intensity of the intervention programs to be implemented for LD students. Also, it is very important to provide in-service training to teachers about how to teach students with LD.

\section{Author's Contributions}

The subject of this study was specified within the scope of the master thesis of the principal author. Prof. Dr. Cevriye Ergül, who is also the advisor of the principal author's master thesis, gave support while reporting the study (research design, data collection, and data analysis). 